\title{
A dual-wavelength photothermal aerosol absorption monitor: design, calibration and performance
}

Luka Drinovec ${ }^{1,2,3}$, Uroš Jagodič ${ }^{1,2}$, Luka Pirker ${ }^{2,4}$, Miha Škarabot ${ }^{2}$, Mario Kurtjak ${ }^{5}$, Kristijan 5 Vidović $^{6}$, Luca Ferrero ${ }^{7}$, Bradley Visser ${ }^{8}$, Jannis Röhrbein ${ }^{8}$, Ernest Weingartner ${ }^{8}$, Daniel M. Kalbermatter ${ }^{9}$, Konstantina Vasilatou ${ }^{9}$, Tobias Bühlmann ${ }^{9}$, Celine Pascale ${ }^{9}$,Thomas Müller ${ }^{10}$, Alfred Wiedensohler ${ }^{10}$, Griša Močnik ${ }^{1,2,3}$

${ }^{1}$ Haze Instruments d.o.o., Ljubljana, Slovenia

${ }^{2}$ Department of Condensed Matter Physics, Jozef Stefan Institute, Ljubljana, Slovenia

${ }^{3}$ Center for Atmospheric Research, University of Nova Gorica, Nova Gorica, Slovenia

${ }^{4}$ Faculty for mathematics and physics, University of Ljubljana, Ljubljana, Slovenia

${ }^{5}$ Advanced Materials Department, Jozef Stefan Institute, Ljubljana, Slovenia

${ }^{6}$ Deparment for Analytical Chemistry, National Institute of Chemistry, Ljubljana, Slovenia

${ }^{7}$ GEMMA center, University of Milano-Bicocca, Milano, Italy

$15{ }^{8}$ Institute for Sensors and Electronics, University of Applied Sciences Northwestern Switzerland, Windisch, Switzerland

${ }^{9}$ Federal Institute of Metrology METAS, Bern, Switzerland

${ }^{10}$ Leibniz Institute for Tropospheric Research, Leipzig, Germany 


\section{Abstract}

There exists a lack of aerosol absorption measurement techniques with low uncertainties and without artefacts. We have developed a two-wavelength Photothermal Aerosol Absorption Monitor (PTAAM-2 $\lambda$ ), which measures the aerosol absorption coefficient at 532 and $1064 \mathrm{~nm}$. Here we describe its design, calibration and mode of operation and evaluate its applicability, limits and uncertainties. The $532 \mathrm{~nm}$ channel was calibrated with $\sim 1 \mu \mathrm{mol} / \mathrm{mol} \mathrm{NO}$, whereas the $1064 \mathrm{~nm}$ channel was calibrated using measured size distribution spectra of nigrosin particles and a Mie calculation. Since the aerosolized nigrosin used for calibration was dry, we determined the imaginary part of the refractive index of nigrosin from the absorbance measurements on solid thin film samples. The obtained refractive index differed considerably from the one determined using aqueous nigrosin solution. PTAAM- $2 \lambda$ has no scattering artefact and features very low uncertainties: $4 \%$ and $6 \%$ for the absorption coefficient at $532 \mathrm{~nm}$ and 1064 respectively; and $9 \%$ for the absorption Ångström exponent. The artefact-free nature of the measurement method allowed us to investigate the artefacts of filter photometers. Both the Aethalometer AE33 and the CLAP suffer from the crosssensitivity to scattering - this scattering artefact is most pronounced for particles smaller than 70 $\mathrm{nm}$. We observed a strong dependence of the filter multiple scattering parameter on the particle size in the 100-500 $\mathrm{nm}$ range. The results from the winter ambient campaign in Ljubljana showed similar multiple scattering parameter values for ambient aerosols and laboratory experiments. The spectral dependence of this parameter resulted in AE33 reporting the absorption Ångström exponent for different soot samples with values biased 0.17-0.3 higher than the PTAAM-2 $\lambda$ measurement. Photothermal interferometry is a promising method for reference aerosol absorption measurements. 


\section{Introduction}

Absorption of sunlight by aerosols, especially black carbon, and the related (semi)indirect effects of these aerosols are collectively the second leading cause of atmospheric warming (Bond et al., 2013). The same light-absorbing aerosols have serious detrimental health effects (Janssen et al., 2011; Janssen et al., 2012). They can be directly emitted into the atmosphere (primary aerosols - black carbon and a fraction of the light-absorbing organic aerosols) or produced in the atmosphere from precursor gases (secondary aerosols - some of the light-absorbing organic aerosols) and their optical properties change with ageing (Saleh et al., 2013; Kumar et al., 2018). Their short atmospheric lifetime (compared to $\mathrm{CO}_{2}$ ) makes them an appealing target for fast abatement and is responsible for their heterogeneity. Climate models do not agree with or capture all the complexity of aerosol absorption observations (Bond et al., 2013; Samset et al., 2018). In order to quantify any reduction in atmospheric heating (Ferrero et al., 2014), aerosol absorption needs to be measured precisely and accurately in many different types of sites, especially regional background sites (Zanatta et al., 2016). Moreover, the measurement of absorption coefficient should be done at different wavelengths for the understanding the direct and semi-indirect aerosol effects on the climate (Samset et al., 2018) and for determining the heating rates, the contribution of sources to these effects and the role of clouds (Ferrero et al., 2021). The increase of absorption at lower wavelengths can be parameterised as an increased absorption Ångström exponent ( $A A E$ ) compared to $A A E=1$ exhibited by black carbon. This increase can be due to the presence of absorbing organic aerosol (Kirchstetter et al., 2004) or organic and inorganic coatings on black carbon (Zhang et al., 2018; Virkkula, 2020). The source (or combustion efficiency) specific AAE can be used in source apportionment of black carbon (Sandradewi et al., 2008; Zotter et al., 2017). However, the measurement of the aerosol absorption coefficient is still a challenging task.

The absorption coefficient has been most often determined using the most practical instrumentation

- filter absorption photometers: the Aethalometer, the Particle Soot Absorption Photometer (PSAP), the Continuous Light Absorption Photometer (CLAP) and the Multiple Angle Absorption Photometer (MAAP) (Rosen et al., 1978; Drinovec et al., 2015; Bond et al., 1999; Ogren et al., 2017; Petzold et al., 2002), where the measurement of light attenuation in the sample-laden filter relative to the clean filter is converted to mass equivalent black carbon concentration (BC) (Petzold et al., 2013) or the

75 absorption coefficient. This type of measurement requires different assumptions which are hard to verify. The enhancement of absorption in the scattering filter matrix and the mass absorption crosssections are two external parameters which need to be determined. Additionally, the measurement is non-linear and the reduction of the sensitivity due to filter loading and the cross-sensitivity to scattering are artefacts, the contributions of which are either assumed (Bond et al., 1999; Ogren et

80 al., 2017) or measured to different extents (Petzold et al., 2002; Drinovec et al., 2015). Postprocessing algorithms were developed to compensate the loading or concentration effects (Weingartner et al., 2003; Virkkula et al., 2007; Collaud Coen et al., 2010; Hyvärinen et al., 2013). These effects are, to a degree, sample dependent, so the data analysis requires more sophisticated approaches (Drinovec et al., 2015; Drinovec et al., 2017) and an additional measurement of scattering is needed (Arnott et al., 2005; Ogren et al., 2017; Yus et al., 2021) to fully compensate for the sensitivity dependence on the sample single-scattering albedo (SSA) and other artefacts.

In situ methods (i.e. without collecting the sample on a filter) offer advantages over filter photometers, such as separate measurements of aerosol extinction and scattering coefficients. The 
integration of these two measurements in a single instrument (Petzold et al., 2013) allows the measurement of these quantities for the exact same sample and calculation of their difference yields the absorption coefficient. Thus, this method was used as a reference for filter photometer characterization (for example, Bond et al., 1999). However, this measurement is still severely restricted when measuring aerosol exhibiting high SSA, as measurement errors of several percent can result in absorption coefficient errors of above $100 \%$, which requires adherence to a strict measurement and data post-processing algorithm to minimize these errors (Modini et al., 2021). On the other hand, the fractal nature of low-SSA black carbon aerosol and the effect of this morphology on the scattering truncation correction of the nephelometer present a systematic source of error also for measurements at low SSA (Modini et al., 2021).

A direct measurement of the aerosol absorption coefficient would therefore avoid the described issues. This is possible in photoacoustic instruments, in which an air sample is drawn through the sample chamber, where it is illuminated with a powerful pump laser beam. The light absorbed by the aerosol is converted to heat, causing an increase of local temperature. Transport of heat causes changes in density and the acoustic wave is amplified in a chamber that acts as an acoustic resonator. The pump beam is modulated and phase-sensitive detection is used to amplify the signal over the measurement noise. Acoustic resonance amplifies the signal by orders of magnitude but needs to be tracked actively to maintain maximum sensitivity. Moreover, the method experiences systematic biases when the sample contains semi-volatile organic coatings or water. As these substances evaporate from the aerosol, the latent heat causes a reduction of the detected acoustic signal (Arnott et al., 2003; Murphy, 2009; Langridge et al., 2013). A comprehensive review of these different approaches can be found in Moosmüller et al. (2009).

Photothermal interferometry similarly employs a modulated pump laser to heat the sample with the absorbed laser light. A second interferometric laser probes the change of the refractive index caused by light absorption and the subsequent heating and decrease of the density of the sample. The response of photothermal interferometer (PTI) to the aerosol absorption coefficient is linear. The 115 first proposed and realized PTI instruments employed a folded Jamin interferometer due to its inherent mechanical stability and a glancing pumping geometry, where the pump beam and the probe interferometric beam overlap at an acute angle in the sample (Moosmüller and Arnott, 1996; Sedlacek, 2006; Sedlacek and Lee, 2007; Lee and Moosmüller, 2020). A novel folded Mach-Zehnder interferometric design employs a single laser for both heating and interferometric detection (Visser et al., 2020).

Standardization, validation and calibration of the aerosol absorption coefficient measurement require well-defined reference samples: particles or absorbing gases (Arnott et al., 2000). The greatest advantage of in situ methods is the ability of calibration with gases (Arnott et al., 2000; Lack et al., 2006, 2012; Nakayama et al., 2015; Davies et al., 2018), while filter photometers need to be compared with each other (Müller et al., 2011; Cuesta-Mosquera et al., 2020) or with other reference instruments (Bond et al., 1999; Arnott et al., 2003) using model aerosols: fullerene soot, spark discharge particles, soot generated with controlled gas combustion, and dyes, especially nigrosin (Bond et al., 1999; Schnaiter et al., 2006; Müller et al., 2011; Cuesta-Mosquera et al., 2020). The advantage of using gases for calibration is conceptual - gas concentration can be measured with great precision and accuracy, and its absorption cross-section is usually well known. It is also practical - gas calibration can be performed in the field, while instruments calibrated with aerosolized 
particles need to be sent to a calibration laboratory as this effort requires a sophisticated setup. $\mathrm{NO}_{2}$, which absorbs strongly in the blue-green part of the spectrum, is a commonly used calibration gas.

Calibration with $\mathrm{NO}_{2}$ is very common, especially for climate studies, because it is usually performed at green wavelengths, where the solar spectrum features a maximum. It is also convenient experimentally thanks to the large absorption cross-section of $\mathrm{NO}_{2}$ in this part of the visible spectrum. However, calibration with gases at longer wavelengths (e.g. in the red or infrared parts of the spectrum) is either extremely challenging or impossible. Yet, these regions are important as they allow the determination of the aerosol absorption wavelength dependence over the whole solar spectrum. This enables a conceptually simple definition of BC, separate from light-absorbing organic aerosols, which feature most of their absorption at lower wavelengths (Kirchstetter et al., 2004; Lack et al., 2008), and the conversion of the optical measurement into BC. To calibrate absorption instruments at longer wavelengths, absorbing particles can be used instead of gases, e.g., Aquadag (Foster et al., 2019), absorbing polystyrene spheres (Lack et al., 2009) and especially nigrosin (Lack et al, 2006; Bluvshtein et al., 2017; Foster et al., 2019). Nigrosin is water soluble and forms spherical aerosols, which can be well described using Mie theory. It has been shown that polydisperse nigrosin can be used for calibration (Foster et al., 2019).

This work describes a novel photothermal interferometer design, which allows for simultaneous and colocated absorption measurements at two wavelengths. The article has been divided into a number of sections to provide a thorough treatment of the instrument: firstly the physical construction of the instrument is described, with a special focus on the novel geometry of the pump and probe beams in the sample chamber. The temporal evolution of the signal measured by the photodiodes during the modulation period of the pump beam and the selection of the modulation frequency is then discussed. Subsequently a noise analysis is performed, showing the sources of noise in the instrument. Following this the operation of the interferometer and the interferometric signal is detailed. A section of the article is then dedicated to the two-wavelength calibration procedure. The linearity of the measurement is demonstrated and the stability and noise of the instrument are determined. Finally, the results obtained with the instrument during a number of laboratory and ambient campaigns are presented. 


\section{Materials and methods}

\subsection{Chemicals}

Nigrosin (Acid black 2, Nigrosin water soluble, CAS 8005-03-6) and ammonium sulphate (Mascagnite, ReagentPlus ${ }^{\circledR}$, CAS 7783-20-2) were obtained from Sigma-Aldrich. Aqueous solutions of nigrosin (labelled, N1-N4) and ammonium sulphate (AS1-AS3) were prepared by dissolving chemicals in ultrapure water (Milli-Q) (Table 1).

Table 1. Designations of the aqueous solutions of nigrosin (N1-N4) and ammonium sulfate which were nebulized.

\begin{tabular}{|l|l|}
\hline Sample & Concentration $(\mathrm{g} / \mathrm{l})$ \\
\hline N1 & 0.01 \\
\hline N2 & 0.1 \\
\hline N3 & 1 \\
\hline N4 & 10 \\
\hline AS1 & 0.01 \\
\hline AS2 & 0.1 \\
\hline AS3 & 1 \\
\hline
\end{tabular}

Solid nigrosin samples were prepared on microscope slides by drying the aqueous solutions of nigrosin (see sample photographs in Supplement S5.3). Glass slides were first cleaned with isopropyl alcohol, then a hydrophilic layer was produced by dipping the slide into a $4 \%$ detergent solution (Hellmanex III) for 30 seconds and flushing the slide with Milli-Q water. Finally $0.2 \mathrm{ml}$ of nigrosin solution was spread on a surface of approx. $6 \mathrm{~cm}^{2}$ and left to dry for 12 hours.

Two bottles of $1 \mu \mathrm{mol} / \mathrm{mol} \mathrm{NO}_{2}$ in synthetic air were acquired (Traceline, Messer Schweiz AG) for the calibration. Calibration of the photothermal aerosol absorption monitor (PTAAM-2 $\lambda$ ) at $532 \mathrm{~nm}$ was performed by filling a 10 I Tedlar $^{\circledR}$ SCV Gas Sampling Bag (Sigma-Aldrich) with the calibration gas and connecting it to the inlet of the instrument.

\subsection{Generation of $\mathrm{NO}_{2}$ reference gas mixture}

Poor stability of reference gas mixtures in the $\mathrm{nmol} / \mathrm{mol}$ range in pressurized cylinders is a wellknown issue for $\mathrm{NO}_{2}$ due to its reactivity (USEPA, 2017; Flores et al., 2021). To generate dynamically SI-traceable $\mathrm{NO}_{2}$ reference gas mixtures at low amount fractions in the field, METAS developed the "traceable mobile permeation generator" (TMPG), which is based on the permeation method (Haerri et al., 2017). The main components of the TMPG are a temperature stabilized permeation chamber, with a calibrated temperature sensor in the chamber, and a calibrated mass flow meter. Calibrated permeation units are placed in the permeation chamber. At a constant temperature, the permeation rate, which here is the transfer of $\mathrm{NO}_{2}$ from the reservoir of the permeation device through its membrane, becomes stable after a stabilization time of at least $24 \mathrm{~h}$. After stabilization, the $\mathrm{NO}_{2}$ reference gas mixture is continuously generated at the desired amount fraction by setting the flow of the dilution gas.

First, the permeation rate of the permeation unit (produced by Fine Metrology S.r.l.s., Italy) containing high purity $\mathrm{NO}_{2}$ was calibrated in a magnetic suspension balance (MSB; Swiss primary 
reference system) at 40 and $45{ }^{\circ} \mathrm{C}$ at an absolute pressure of 1080 mbar in synthetic air 5.6 for several days. The permeation unit was then placed in the permeation chamber of the TMPG that mimics the conditions in the MSB. TMPG was sent to Ljubljana. After 4 days of stabilization the generated gas was used for calibration of PTAAM- $2 \lambda$ and CAPS $\mathrm{NO}_{2}$ monitors. After shipment back to METAS the permeator was again analyzed in MSB.

\subsection{Laboratory aerosol generation}

Nigrosin and ammonium sulfate aerosols were generated using the ATM 226 nebulizer (Topas GmbH, Germany) set to $4 \mathrm{lpm}$ sample flow. The nebulizer was connected to diffusion driers to reduce relative humidity below $30 \%$.

\subsection{Soot samples}

Diesel exhaust was collected from the tailpipe of a EURO3 Volkswagen Passat 1.9 TDI at $2500 \mathrm{rpm}$. An average black carbon emission factor of $1.31 \mathrm{~g} / \mathrm{kg}$ was previously determined for the selected vehicle (Ježek et al., 2015).

Soot generated by a miniCAST 5201 Type BC (Jing Ltd., Switzerland) was also used as a test aerosol. The physical and optical properties of the soot particles have been reported elsewhere (Ess et al., 2021).

210 Propane soot samples were obtained by collecting the exhaust of a portable propane burner/torch. After ignition the air inlets were closed to generate fuel-rich combustion. Because of slow sample dilution large soot agglomerates were formed.

\subsection{Absorbance measurements}

Absorbance of nigrosin was measured using a Shimadzu UV-3600 UV-VIS-NIR Spectrophotometer (Shimadzu, Japan). Aqueous solutions of nigrosin were measured in the 10-mm-path quartz cuvette. Solid nigrosin samples were placed at the entrance of the ISR-3100 integrating sphere, which collected all the transmitted illumination.

\subsection{Reflectance measurements}

Reflectance of nigrosin using a perpendicular beam at 520 and $1064 \mathrm{~nm}$ was measured to correct for the reflection losses during the absorbance measurements. Reflectance was calculated by dividing the intensity of the reflected beam with that of the incident beam.

To determine the real part of the refractive index, a measurement of the Brewster $\theta_{B}$ angle was performed at 633 and $1064 \mathrm{~nm}$. Measurement was performed on a thick film of nigrosin on a glass slide.

\subsection{Online instrumentation}

The size distribution of the aerosol particles was measured using a scanning mobility particle sizer (TSI model 3936L75). The instrument was used with an impactor with a $0.0508 \mathrm{~cm}$ nozzle. Measured spectra were corrected using the diffusion and the multiple charge correction algorithams. Scattering was measured with the Aurora 4000 - Polar Nephelometer (Ecotech, Australia) set to measure the total and back scattering coefficient. 
Two filter photometers, an Aethalometer model AE33 (Magee Scientific, USA) and a CLAP (Haze Instruments, Slovenia) were used to obtain attenuation coefficients. The AE33 features a built-in filter loading compensation algorithm (Drinovec et al., 2015) and was using the M8060 filter. The CLAP was run using the Azumi $371 \mathrm{M}$ filter and the data have been compensated manually using the algorithm by Ogren et al. (2017).

Two $\mathrm{NO}_{2}$ monitors based on cavity ring-down spectroscopy were used to determine $\mathrm{NO}_{2}$ amount fraction. In 2020, a NO 2 analyzer - model T500U (Teledyne, USA) was used. In 2021, the $\mathrm{CAPS} \mathrm{NO}_{2}$ monitor (Aerodyne research, USA) was used.

\subsection{Offline instrumentation}

240 To determine the morphology of the diesel exhaust, propane soot, and nigrosin samples, a FEI HeliosNanolab 650 (Thermo Fischer Scientific, Waltham, MA, USA) scanning electron microscope (SEM) operating at $1 \mathrm{kV}$ accelerating voltage was used. The samples were mounted on SEM holders with carbon tape and coated with a few nm of carbon to prevent charging effects.

To determine the laser stability during warmup and operation, the spectra of the $532 \mathrm{~nm}$ DPSS laser were measured with a spectrometer (Shamrock SR-500i, Andor) equipped with a cooled EMCCD camera (Newton DU970N, Andor).

An atomic force microscope (AFM) Nanoscope Illa - MultiMode AFM (Digital Instruments, Santa Barbara, CA) equipped with J scanner (100 $\mu \mathrm{m}$ horizontal range) operating in contact mode was used to determine the thickness of the solid nigrosin samples. Measurements were performed by carving a groove in the thin layer of the nigrosin sample all the way down to the glass substrate and measuring the depth of the groove.

\subsection{Mie calculation}

Mie calculations were performed using Matlab routines for homogeneous spheres (Mätzler, 2002).

\subsection{Measurement campaigns}

The presented data was collected during several measurement campaigns:

- Ljubljana ambient winter campaign 2020: duration: 26 Feb 2020 - 24 Mar 2020; instrumentation: the PTAAM-2 $\lambda$ and the AE33.

- Ljubljana laboratory campaign 2020: first PTAAM-2 $\lambda$ characterization campaign; instrumentation: Aurora 4000, AE33, CLAP, Teledyne $\mathrm{NO}_{2}$ monitor;

260 - AeroTox laboratory campaign 2020: study on the influence of coating on absorption (Kalbermatter et al., 2021); PTAAM- $2 \lambda$ and SMPS measurements of the uncoated CAST soot and nigrosin are used here

- Ljubljana laboratory campaign 2021: additional PTAAM-2 $\lambda$ characterization measurements; instrumentation: Aurora 4000, AE33, CLAP, Aerodyne research $\mathrm{NO}_{2}$ monitor; SMPS. 


\section{The instrument description}

\subsection{The instrument setup}

The dual-wavelength photothermal aerosol absorption monitor (PTAAM-2 $\lambda$ ) uses the photothermal effect to measure aerosol absorption. A folded Mach-Zehnder interferometer is used to measure the difference of the optical path between the two interferometer beams (Figure 1). For the probe beam a HeNe laser is coupled into a polarisation-maintaining single mode fiber. The beam exits the fiber via a fiber collimator providing a $0.25 \mathrm{~mm}$ diameter free-space beam, which is split into two interferometer beams within a beam-splitter block. The returning beams are combined and the intensity is measured using silicon photodiodes PD1 and PD2 connected to the lock-in amplifier (Zurich instruments, model MFLI).

The sample cell contains pressure, temperature and relative humidity sensors. The interferometer is sealed in the enclosure to protect it from acoustic noise and pressure fluctuations. The optical path length of one of the interferometer beams is controlled by a pressure cell connected to a computercontrolled syringe pump.

A $2 \mathrm{~W}$ frequency-doubled Nd:YAG laser $(532 \mathrm{~nm}$ ) and a $3 \mathrm{~W} \mathrm{Nd:YAG} \mathrm{(1064} \mathrm{nm}$ ) laser are coupled to the multimode optical fibers. Parts of these fibers are shaken by an electromagnetic actuator to homogenise the profiles of the beams exiting the fibers. The pump beams, which are modulated at different frequencies, are collimated and introduced by dichroic mirrors into the interferometer. The powers of the pump beams are monitored with photodiodes $\mathrm{P} 1$ and $\mathrm{P} 2$.

285

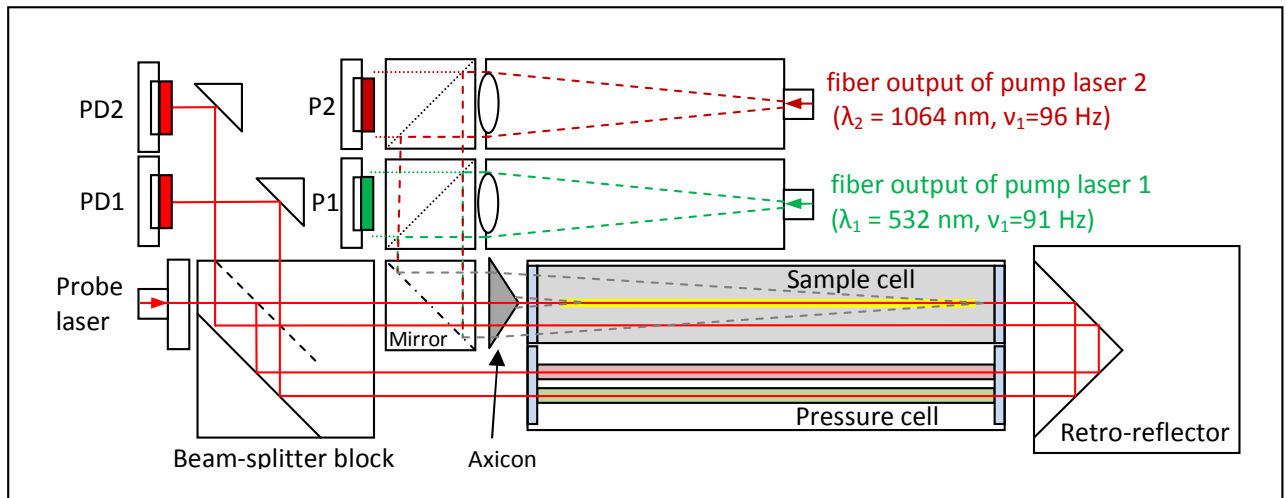

Figure 1. Schematic representation of the PTAAM-2 $\lambda$ setup. 
A new photothermal interferometer configuration is utilised which uses an axicon to focus the pump beams into the sample chamber where they overlap with the probe beam (Drinovec and Močnik, 2020). The pump beams exiting the fibers are collimated and subsequently combined using two dichroic mirrors and then directed into the measuring chamber using a custom drilled mirror - two drilled holes allow the interferometer beams to pass through the mirror without interacting with the pump beam. A custom axicon, drilled to allow passage of the probe beams, is used to provide an elongated focus of the pump beams along the axis of the probe beam inside the sample cell. The diameters of the probe and pump beams in the sample cell are shown in Figure 2. The pump beams are aligned with the probe beam using a CCD camera. During one and a half years of instrument testing (including road shipment in excess of $3000 \mathrm{~km}$ to the two measurement campaigns) there was no need to realign the optics.

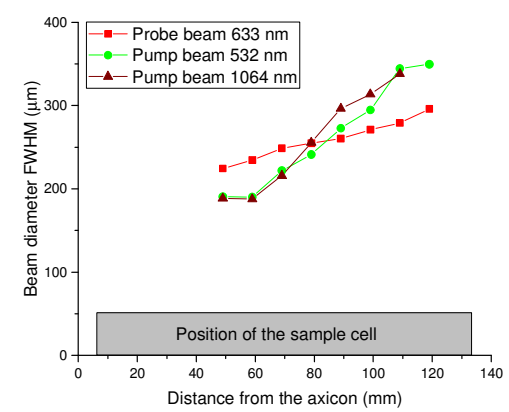

Figure 2. Beam diameters of probe and pump beams inside the sample cell. Beam sizes closer to the axicon could not be measured due to mechanical restrictions.

This setup allows for simultaneous measurement of absorption at two wavelengths in the same sample volume by modulating the probe beams at different frequencies $(91 \mathrm{~Hz}$ and $96 \mathrm{~Hz}$, for example). The retention time of the aerosol particles in the pump beam (approx. 5 seconds for a 100 $\mathrm{nm}$ particle) is much longer compared to the duration of the modulation interval (11 ms).

For "in situ" aerosol absorption measurement the pump beam intensity should be kept low enough so that the heating does not modify the physical properties of the particles. The use of an axicon for focusing the pump beams results in a pump illumination intensity of approx. $2 \mathrm{~W} / \mathrm{mm}^{2}$, which is much lower compared to the glancing setup (Sedlacek, 2006) and the modulated single-beam PTI (Visser et al., 2020). 


\subsection{Photothermal effect}

When the sample air is illuminated with the pump beam, some of the light is absorbed by the gases and particles in the sample. Heat is then transferred to the surrounding air causing an increase of temperature. This, in turn, causes a small reduction in the air refractive index. This change of the refractive index is measured as the reduction of the optical path in the folded Mach-Zehnder interferometer.

The pump beam is modulated ON/OFF with a $50 \%$ duty cycle. When the pump beam is switched ON, there is first a linear increase of the photodiode voltage which later starts to saturate due to increasing heat transfer to the surrounding air (Figure 3). The exact shape of the detected voltage depends on the intensity profile of the pump beam during the heating period and the geometry of the pump and probe beams. For the pump frequencies between 90 and $100 \mathrm{~Hz}$, we observed an exponential rise and decay of the detector voltage during the ON and OFF part of the modulation period. Here, we show the results obtained for nigrosin using pump lasers operating at $532 \mathrm{~nm}$ and $1064 \mathrm{~nm}$. The amplitude of the $532 \mathrm{~nm}$ channel voltage is approximately 7-fold higher compared to the $1064 \mathrm{~nm}$ channel, but the shape does not change with amplitude. Therefore, nonlinearities in the instrument response can be avoided and a lock-in amplifier can be used to measure the amplitude of the photodiode voltage.

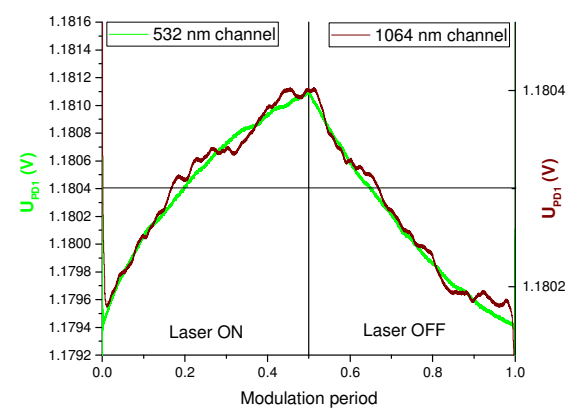

Figure 3. Average photodiode voltage during the heating and cooling parts of the modulation period for the $532 \mathrm{~nm}$ and the $1064 \mathrm{~nm}$ channels obtained for nigrosin particles. The duration of the modulation period is $\mathbf{1 1 . 1} \mathrm{ms}$ and $\mathbf{1 0 . 4} \mathrm{ms}$, respectively. The curves are obtained by averaging the photodiode PD1 voltage over more than 10000 modulation periods. 
When the optical path of the interferometer changes, we observe a voltage increase on one of the photodiodes and a decrease on the other. To increase the signal-to-noise ratio, the difference between the photodiode voltages $\left(U_{P D 1}-U_{P D 2}\right)$ is used to calculate the photothermal signal. This difference is fed to the lock-in amplifier using the pump beam modulation frequency as the reference frequency. The lock-in amplifier multiplies the signal with a sine/cosine function at the modulation frequency and filters out other frequencies; this results in two output signals, $U_{x}$ and $U_{y}$, which represent the dynamic components phase-shifted by $\pi / 2$. The highest lock-in signal for the selected modulation frequency is obtained at a certain phase $\beta$, being approx. 2 rad for a modulation frequency of $91 \mathrm{~Hz}$. The projection of the lock-in signal is calculated as a scalar product:

$$
S=U_{x} \cos (\beta)+U_{y} \sin (\beta)
$$

The instrument response $S$ strongly depends on the duration of the modulation period (Figure 4). The signal increases with the duration of the modulation period, but shows a saturation effect because of the increased heat transfer. In general, the measurement noise (defined as standard deviation of the $1 \mathrm{~s}$ data) also increases with the length of the modulation interval. The optimum modulation frequency is selected by the best signal-to-noise ratio.

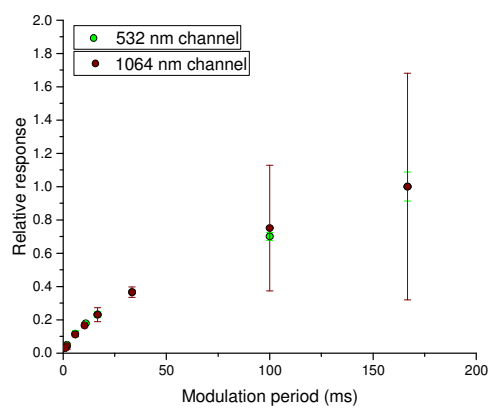

Figure 4. Instrument response $S$ (lock-in amplifier signal at the optimum phase) at different durations of the modulation period. The responses are normalised to the response at $167 \mathrm{~ms}$. The error bars designate a standard deviation of $1 \mathrm{~s}$ data.

Increased noise at lower frequencies can also be observed on fast Fourier transformation of the photodiode signal (Figure S3). Noise is highest below $10 \mathrm{~Hz}$, there is a plateau between 10 and 100 $\mathrm{Hz}$, and increased noise between $200-300 \mathrm{~Hz}$. There are also certain noise peaks, which should be avoided to reduce the measurement noise. Frequencies of 91 and $96 \mathrm{~Hz}$ were selected to attain the highest signal-to-noise ratio.

When there is no absorbing sample in the measurement cell, it is possible to measure an offset with the magnitude of $8 \mu \mathrm{V}$ for the $532 \mathrm{~nm}$ channel and $39 \mu \mathrm{V}$ for the $1064 \mathrm{~nm}$ channel. This offset is generated in phase with the measurement frequency. The main sources of the offset are electronic interaction (signal at the pump frequencies is leaked into the photodiode signal) and interaction of the pump beam with the probe beam on the shared optical elements. Variation of the offset is an additional source of measurement noise. 
There are several sources of noise which are independent of the pump frequency, including the noise of probe lasers, photodiodes, sample air flow turbulences, pump laser power oscillations, mechanical resonances of the optical elements and random electronic noise. The sources of noise were investigated by comparing different experimental setups (Figure 5):

- "PD": pump and probe lasers switched OFF; noise is generated by photodiodes and electronics.

- "HeNe": HeNe probe laser is switched ON with one of the interferometer arms blocked; measured noise comes from the variation of the HeNe laser power.

- "Interferometer": HeNe probe laser is switched ON; this is a measure of the interferometer noise.

- "Interferometer + flow": HeNe probe laser is switched ON, sample flow $(0.4 \mathrm{lpm})$ is switched ON; there is some increase of noise due to the airflow in the sample cell.

- "Interferometer + pump beam": Probe and pump lasers and sample flow are switched ON; the noise coming from offset variation is added.

The results show that the majority of the noise comes from the interferometer. It may be related to the vibration of the optical elements of the interferometer. For the $1064 \mathrm{~nm}$ channel about one half of the noise is caused by the offset variation.
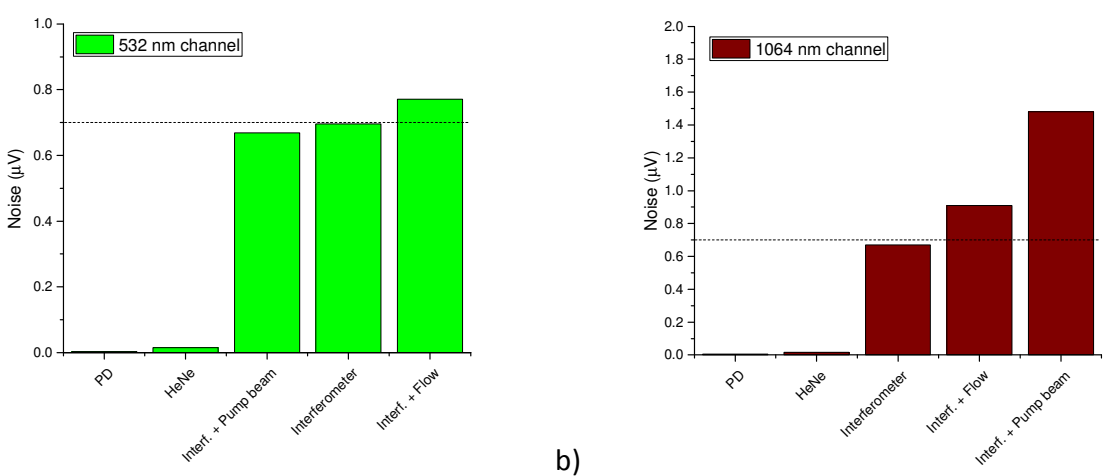

Figure 5. Contribution of different sources to the measurement noise (standard deviation of signal) for the $532 \mathrm{~nm}$ channel (a) and the $1064 \mathrm{~nm}$ channel (b) run at 91 and $96 \mathrm{~Hz}$, respectively. Settings: "PD" - photodiode noise, "HeNe" - noise of the HeNe laser (blocked one of the interferometer arms), "Interferometer" - noise of the interferometer, "Interf. + Flow" - interferometer noise for sample flow switched on, "Interf. + Pump beam" - interferometer with a pump beam switched on. 


\subsection{Calculation of the PTAAM- $2 \lambda$ signal}

The response of photothermal interferometer is highest when the interferometer is operating in the so-called quadrature point - where the difference of the optical paths between the two arms of the interferometer is exactly $\lambda / 4$. The interferometer response in the quadrature point is linear, as photodiode voltages in both interferometric arms intersect at the steepest (and linear) part of the sine curve (Figure 6). The quadrature point can be determined by performing an interferometric scan (measurement of the photodiode signal while changing the optical path difference). The pressure cell is used to regulate the optical path of one interferometer arm to maintain the interferometer in the quadrature point.

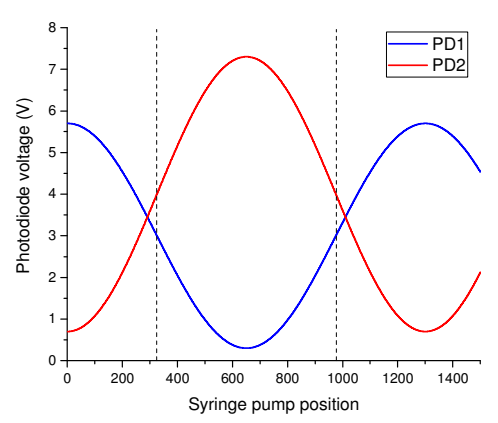

Figure 6. The interferometer scan of photodiode PD1 and PD2 voltages is performed by changing the optical path of one of the interferometer arms using the pressure cell. A $1 \lambda$ difference in optical path corresponds to 1300 steps of the syringe pump. Quadrature points are marked by dashed lines.

For an interferometer in the quadrature point, the lock-in signal is proportional to the amplitude of the interferometer signal $\mathrm{U}_{10}$. It is determined from the maximum and minimum voltages for both photodiodes determined during the interferometer scan:

$$
U_{I 0}=\frac{U_{P D 1 \max }-U_{P D 1 \min }+U_{P D 2 \max }-U_{P D 2 \min }}{4} .
$$

Because the HeNe laser intensity slowly changes with time, a special procedure to determine the instantaneous interferometer amplitude $U_{\text {, }}$ was developed, which holds when the interferometer is in the quadrature point:

$$
U_{I}=\left(\frac{U_{P D 1}+U_{P D 2}}{U_{P D 10}+U_{P D 20}}\right) U_{I 0}
$$

$420 U_{P D 1}$ and $U_{P D 2}$ are the instantaneous photodiode signals in the quadrature point, and $U_{P D 10}$ and $U_{P D 20}$ the photodiode signals in the quadrature point when the interferometer scan was performed. The projections of the lock-in signals for the two channels are:

$$
\begin{aligned}
& S_{532 \mathrm{~nm}}=U_{x, 532 \mathrm{~nm}} \cos \left(\beta_{532 \mathrm{~nm}}\right)+U_{y, 532 \mathrm{~nm}} \sin \left(\beta_{532 \mathrm{~nm}}\right), \\
& S_{1064 \mathrm{~nm}}=U_{x, 1064 \mathrm{~nm}} \cos \left(\beta_{1064 \mathrm{~nm}}\right)+U_{y, 1064 \mathrm{~nm}} \sin \left(\beta_{1064 \mathrm{~nm}}\right) .
\end{aligned}
$$


425 The absorption coefficient is calculated by dividing $S$ with the instantaneous interferometer amplitude $U_{1}$, reported at the selected pressure $p_{0}$ and temperature $T_{0}$, where $p$ and $T$ represent instantaneous conditions. The response is adjusted by the calibration constant $A$ and the ratio between the nominal $P_{\lambda, 0}$ and instantaneous pump laser power $P_{\lambda}$, separately for each channel:

$$
b_{a b s, 532 n m, t o t a l}=A_{532 n m}\left(\frac{S_{532 n m}}{U_{I}}\right)\left(\frac{p_{0}}{p}\right)\left(\frac{T}{T_{0}}\right)\left(\frac{P_{532 n m, 0}}{P_{532 n m}}\right),
$$

430

$$
b_{a b s, 1064 n m, \text { total }}=A_{1064 n m}\left(\frac{S_{1064 n m}}{U_{I}}\right)\left(\frac{p_{0}}{p}\right)\left(\frac{T}{T_{0}}\right)\left(\frac{P_{1064 n m, 0}}{P_{1064 n m}}\right) .
$$

The baseline offset is determined for the filtered air sample and subtracted from the total signal to provide the absorption coefficients $b_{a b s, 532 \mathrm{~nm}}$ and $b_{a b s, 1064 \mathrm{~nm}}$ :

$$
\begin{aligned}
& b_{a b s, 532 \mathrm{~nm}}=b_{a b s, 532 \mathrm{~nm}, \mathrm{total}}-b_{a b s, 532 \mathrm{~nm}, \text { off set }}, \\
& b_{a b s, 1064 \mathrm{~nm}}=b_{a b s, 1064 \mathrm{~nm}, \mathrm{total}}-b_{a b s, 1064 \mathrm{~nm}, \text { off set }} .
\end{aligned}
$$




\section{Calibration of the PTAAM-2 $\lambda$}

440 The instrumental response depends on the overlap between probe and pump beams. After beam alignment, which proved very stable over a very long period, both channels need to be calibrated.

\subsection{Calibration of the $532 \mathrm{~nm}$ channel}

Similarly to the calibration of photoacoustic instruments (Arnott et al., 2000; Lack et al., 2006; Bluvshtein et al., 2017), we decided to use $\mathrm{NO}_{2}$ for calibration of the $532 \mathrm{~nm}$ channel. An absorption cross-section of $1.47 * 10^{-19} \mathrm{~cm}^{2}$ was determined from the measured laser spectrum and the highresolution absorption spectrum of $\mathrm{NO}_{2}$ by Vandaele et al (2001) (Supplement S4). An absorption coefficient of $1 \mu \mathrm{mol} / \mathrm{mol} \mathrm{NO}$ at $100 \mathrm{kPa}$ and $25^{\circ} \mathrm{C}$ of $357.3 \mathrm{Mm}^{-1}$ was obtained.

Calibration of the $532 \mathrm{~nm}$ channel was performed by filling the Tedlar bag (Sigma-Aldrich) with $\mathrm{NO}_{2}$ from the bottle of nominally $1 \mu \mathrm{mol} / \mathrm{mol} \mathrm{NO}_{2}$ in synthetic air (Messer Schweiz AG). This procedure features much lower noise compared to connecting the instrument inlet directly to the bottle. The Tedlar bag was filled with $\mathrm{NO}_{2}$ and emptied several times to passivate the bag's inner surface. After the passivation procedure the $\mathrm{NO}_{2}$ amount fraction in the bag agreed within $1 \%$ with the source concentration. During the offset measurement, a second Tedlar bag, filled with synthetic air, was sampled.

455 The measured $\mathrm{NO}_{2}$ amount fraction of different bottles with nominal amount fraction of $1 \mu \mathrm{mol} / \mathrm{mol}$ differed up to $21 \%$. To reduce this uncertainty we performed the calibration with Traceable Mobile Permeation Generator" (TMPG) developed by METAS (Haerri et al., 2017). The generated amount fraction of $\mathrm{NO}_{2}$ during the campaign in Slovenia was $292 \mathrm{nmol} / \mathrm{mol}$ with the expanded measurement uncertainty of +12 and $-3 \mathrm{nmol} / \mathrm{mol}(\mathrm{k}=2)$. This value was used to determine the accurate amount fractions of $\mathrm{NO}_{2}$ in the bottles used for calibration. The calibration parameter $\mathrm{A}_{532 \mathrm{~nm}}$ was calculated taking into account the measured losses of $\mathrm{NO}_{2}$ and particles in the instrument sample lines.

\subsection{Calibration of the $1064 \mathrm{~nm}$ channel}

Calibration of the $1064 \mathrm{~nm}$ channel is more complicated as there are no appropriate absorbing gases available at that wavelength. Particles with known optical properties can be used here to transfer the calibration from the $\mathrm{NO}_{2}$ calibrated $532 \mathrm{~nm}$ channel to $1064 \mathrm{~nm}$ as proposed by Arnott et al. (2000) and Foster et al. (2019). We decided to use water soluble nigrosin (Acid black 2, CAS 8005-03-6) because it forms spherical particles when nebulized and dried (Supplement S6). To calibrate the 1064 $\mathrm{nm}$ channel, the absorption ratio $b_{\mathrm{abs}, 1064 \mathrm{~nm}} / \mathrm{b}_{\mathrm{abs}, 532 \mathrm{~nm}}$ needs to be calculated. The absoprtion ratio is determined using Mie calculations based on:

- sphericity of nigrosin particles confirmed by scanning electron microscopy (Supplement S6),

- nigrosin particle size distribution measured with SMPS,

- the complex refractive index of solid nigrosin at $532 \mathrm{~nm}$ and $1064 \mathrm{~nm}$. 
With respect to the nigrosin refractive index investigation, the imaginary part can be determined were conducted (Supplement S5). The absorbance of the aqueous solution of nigrosin was measured in a 1-cm-path cuvette. Solid nigrosin samples were produced by drying nigrosin solution on the microscope slides. The absorbance of the solid nigrosin film on these slides was measured with an integrating sphere spectrometer. The results show large (up to $\pm 30 \%$ ) differences in the imaginary part of the refractive index between the aqueous and solid nigrosin (Figure 7). This means that calculating absorption using aqueous solution data can lead to substantial systematic errors. The imaginary part of the solid nigrosin refractive index at $532 \mathrm{~nm}$ was determined to be 0.223 which is somewhat lower compared to 0.26 obtained by Bluvshtein et al., (2017). This difference can be attributed to the variability in the nigrosin quality provided by the manufacturer or the measurement method.

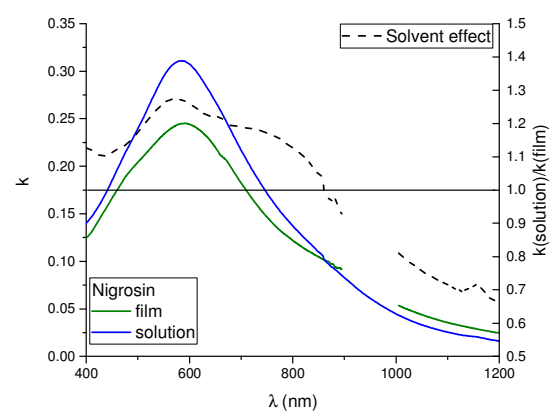

Figure 7. The imaginary part of the refractive index $\mathbf{k}$ determined for solid nigrosin film and its aqueous solution. The solvent effect, the ratio of the determined imaginary parts of the refractive index, is marked by the dashed line.

490 Since the real part of the refractive index in infrared has not yet been reported, a measurement of the Brewster angle at $1064 \mathrm{~nm}$ was performed (Supplement S5.1) and determined the real part of the refractive index to be $1.848 \pm 0.005$. We also determined the refractive index at $633 \mathrm{~nm}$ to be $1.81 \pm 0.01$, which agreed well with the value of 1.78 obtained by Bluvshtein et al. (2017). This allowed us to use the real part of the refractive index at $532 \mathrm{~nm}$ from Bluvshtein et al. (2017). The following values of the refractive index have been used for Mie calculations:

$$
\begin{aligned}
& n(532 n m)=1.64+0.223 i \\
& n(1064 n m)=1.85+0.0419 i
\end{aligned}
$$


Nigrosin particles were generated using the Topas ATM 226 nebulizer with a $0.1 \mathrm{~g} / \mathrm{l}$ nigrosin solution calculation was performed for each size channel separately and summed together to obtain the absorption coefficients at 532 and $1064 \mathrm{~nm}$. The calculated absorption ratio $b_{a b s, 1064 \mathrm{~nm}} / \mathrm{b}_{\mathrm{abs}, 532 \mathrm{~nm}}$ for different particle sizes is quite flat between 15 and $300 \mathrm{~nm}$ (Figure 8.a). Calculation of the absorption ratio for different polydisperse distributions shows it to be stable for a wide range of sizes: for aerosolized nigrosin with a number mode size between $30 \mathrm{~nm}$ and $60 \mathrm{~nm}$ there is only $2 \%$ variation of the absorption ratio (Figure $8 . b$ ). This shows that the calibration with nigrosin is quite a robust procedure not depending greatly on the nigrosin size distribution.

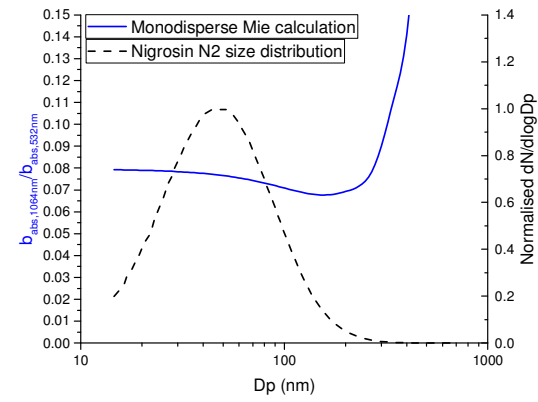

a)

Figure 8. a) The absorption ratio $b_{a b s, 1064 \mathrm{~nm}} / b_{a b s, 532}$ calculated for monodisperse nigrosin (blue) and an example of the size distribution for the aerosolized nigrosin solution N2. b) Modelled absorption ratio calculated for various log-normal size distributions. The number size mode of aerosolized nigrosin samples N1, N2 and N3 is marked.

During different measurement campaigns the absorption ratio was calculated for the measured nigrosin size distributions. Due to the increased measurement uncertainties for particles bigger than $400 \mathrm{~nm}$ these data was not used for Mie calculation. Absorption ratio obtained with sample N2 ranged between 0.0733 and 0.0764 (Supplement S3.5). The calibration parameter $A_{1064 n m}$ was adjusted so that the measured absorption ratio agrees with the calculated value. 


\subsection{Validation of Mie calculation at $532 \mathrm{~nm}$}

520 The $532 \mathrm{~nm}$ channel of the PTAAM-2 $\lambda$ is calibrated using $\mathrm{NO}_{2}$, which allows the validation of the Mie calculation of nigrosin particle optical properties at that wavelength. The comparison was performed for several nigrosin measurements during the AeroTox 2020 and Ljubljana 2021 campaigns (Table 2). For the AeroTox campaign, the average Mie calculated absorption was $6 \%$ while scattering was $17 \%$ higher compared to the measurement. For the Ljubljana 2021 campaign, the average Mie calculated absorption was $24 \%$ higher compared to the measurement and the scattering was $26 \%$ higher. The biases of Mie calculated absorption and scattering are similar, indicating a similar source for both parameters - that the uncertainty of the SMPS measurements might play a role. Based on our experience, we believe that the absorption coefficient at $532 \mathrm{~nm}$ measured by PTAAM- $2 \lambda$ agrees with the Mie calculation based on particle size distributions measured by a well maintained SMPS instrument.

Table 2. Mie calculated and measured absorption and scattering coefficients at $532 \mathrm{~nm}$ for aerosolized nigrosin N2 for several independent experiments (designated A, B, C) during the AeroTox 2020 and Ljubljana 2021 campaigns. Size distribution below $400 \mathrm{~nm}$ was used for Mie calculation. Experiment mean values and standard errors are presented.

\begin{tabular}{|l|l|l|l|l|l|l|}
\hline & $\begin{array}{l}\text { babs_Mie } \\
\text { (Mm-1) }\end{array}$ & $\begin{array}{l}\text { babs_meas. } \\
\text { (Mm-1) }\end{array}$ & $\begin{array}{l}\text { babs } \\
\text { Mie/meas. }\end{array}$ & $\begin{array}{l}\text { bscat_Mie } \\
\text { (Mm-1) }\end{array}$ & $\begin{array}{l}\text { bscat_meas. } \\
\text { (Mm-1) }\end{array}$ & $\begin{array}{l}\text { bscat } \\
\text { Mie/meas. }\end{array}$ \\
\hline AeroTox 2020_A & $692+/-4$ & $628.6+/-0.3$ & 1.10 & $311+/-4$ & $269+/-1$ & 1.16 \\
\hline AeroTox 2020_B & $494+/-2$ & $463.6+/-0.3$ & 1.07 & $260+/-2$ & $214+/-1$ & 1.21 \\
\hline AeroTox 2020_C & $705+/-4$ & $696.2+/-0.5$ & 1.01 & $378+/-5$ & $329+/-2$ & 1.15 \\
\hline Ljubljana 2021_A & $597+/-6$ & $431+/-1.3$ & 1.38 & $274+/-1$ & $198.8+/-0.3$ & 1.38 \\
\hline Ljubljana 2021_B & $625+/-4$ & $508+/-0.6$ & 1.23 & $295+/-1$ & $242.7+/-0.3$ & 1.22 \\
\hline Ljubljana 2021_C & $537+/-7$ & $505+/-0.6$ & 1.06 & $253+/-1$ & $214.0+/-0.3$ & 1.18 \\
\hline
\end{tabular}




\section{Results}

\subsection{PTAAM-2 $\lambda$ stability and noise}

Before conducting the measurement campaigns, the PTAAM- $2 \lambda$ was calibrated using $\sim 1 \mu \mathrm{mol} / \mathrm{mol}$ $\mathrm{NO}_{2}$ gas and aerosolized nigrosin particles. The same procedure was used to validate the instrument sensitivity during the Ljubljana 2020 campaign (Figure 9) assuming a stable $\mathrm{NO}_{2}$ amount fraction and nigrosin absorption ratio. The $532 \mathrm{~nm}$ channel was very stable with $1 \%$ variation during one week of the campaign. For the $1064 \mathrm{~nm}$ channel the variation was higher at $3 \%$ and showed a slow decline. A very stable instrument sensitivity was also obtained during the AeroTox campaign (Kalbermatter et al., 2021).

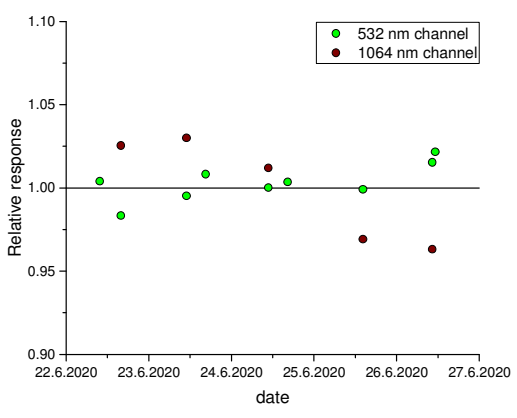

a)

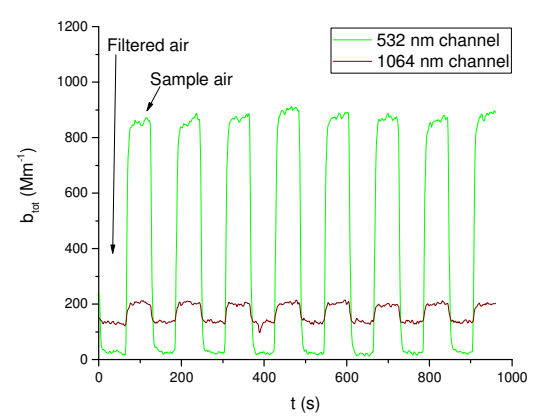

b)

Figure 9. Validation of the PTAAM- $2 \lambda$ sensitivity during the Ljubljana 2020 campaign. Validation was performed by repeating the calibration experiments. Figure $b$ shows the signal during nigrosin calibration. To obtain the absorption coefficient of nigrosin, the offset obtained for filtered air was 
Absorption measurements with the PTAAM- $2 \lambda$ are performed by first measuring the filtered air to determine the baseline offset, with the procedure being performed automatically using the internal HEPA filter (Figure 9.b). This offset is later subtracted from the measurement of the sample air. During the Ljubljana 2020 campaign we measured offsets of $29 \mathrm{Mm}^{-1}$ and $145 \mathrm{Mm}^{-1}$, and standard deviations of $6 \mathrm{Mm}^{-1}$ and $7 \mathrm{Mm}^{-1}$ for the $532 \mathrm{~nm}$ and the $1064 \mathrm{~nm}$ channels, respectively (Figure 10.a). When applying an additional external HEPA filter, the calculated absorption signal was close to zero with similar standard deviation as observed for the offset.The noise of the instrument was analysed in detail by calculating the Allan variance. The Allan plot of the instrument noise shows a peak which is characteristic for the smoothed data (Figure 10.b) and is related to the filtering functions used in the lock-in amplifier. For the $532 \mathrm{~nm}$ channel we observe a linear decrease of the Allan variance with $\tau$. For the $1064 \mathrm{~nm}$ channel the slope is lower due to noise caused by the slow variation of the offset.

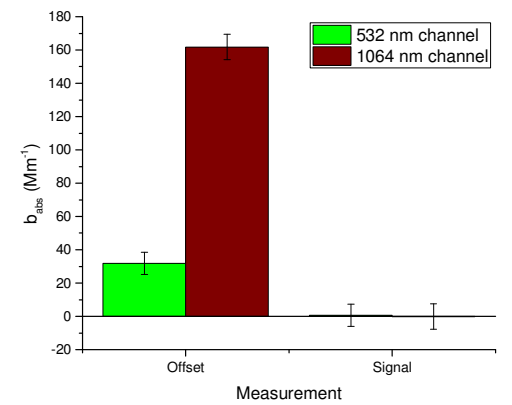

a)

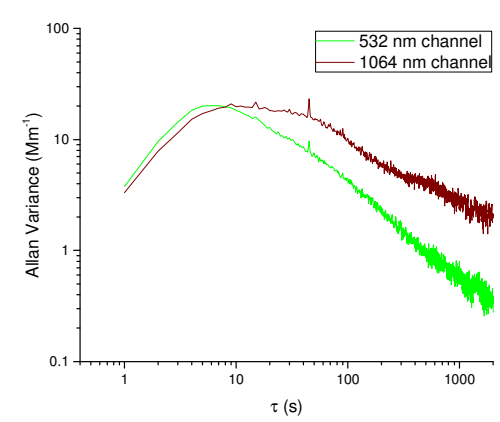

b)

565 Figure 10. Average value and standard deviation of the offset and signal for filtered air (a); Allan variance (b). 


\subsection{PTAAM-2 $\lambda$ response linearity for gas and particles}

The linearity of the instrument response was tested with absorbing gases and particles. For $\mathrm{NO}_{2}$ samples with amount fraction below $1 \mu \mathrm{mol} / \mathrm{mol}$ we observed a linear response for the $532 \mathrm{~nm}$ channel with a $\mathrm{R}^{2}$ value of 0.9996 (Figure 11.a). The measurement at $1064 \mathrm{~nm}$ confirms that $\mathrm{NO}_{2}$ does not absorb at this wavelength. The linearity was also tested using nigrosin particles. Since the size distribution of the particles was stable, we were able to use the scattering coefficient as a reference parameter proportional to the particle concentration. The absorption of nigrosin particles was linear with the scattering signal in the absorption range up to $1200 \mathrm{Mm}^{-1}$ for the $532 \mathrm{~nm}$ channel and up to 100 for the $1064 \mathrm{~nm}$ channel (Figure 11.b), with the corresponding $\mathrm{R}^{2}$ values of 0.997 and 0.968 , respectively.

a)

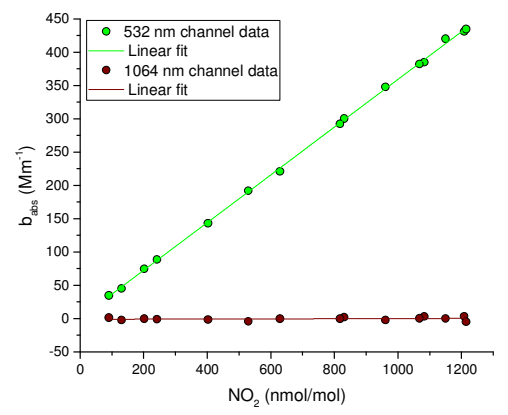

Figure 11. Instrument response to different amount fractions of $\mathrm{NO}_{2}(\mathrm{a})$ and nigrosin particles (b).

Interestingly, the noise behaviour for gas measurements differs substantially from that of particle measurements (Figure 12). There is no significant increase in noise (standard deviation at $1 \mathrm{~s}$ time resolution) with the $\mathrm{NO}_{2}$ amount fraction. For nigrosin particles the noise increases linearly with the absorption signal and converges toward $1 \%$ of the signal. For $\mathrm{NO}_{2}$, light is absorbed directly by the gas, in contrast to nigrosin, for which heat is transferred from the particles to the gas. This may result in transient temperature inhomogeneities in the sample volume.

a)

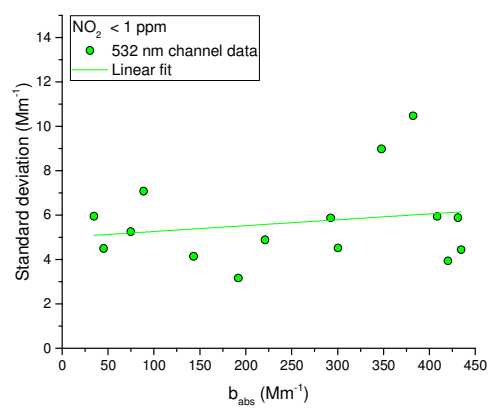

Figure 12. Standard deviation of the $532 \mathrm{~nm}$ channel data during measurement of $\mathrm{NO}_{2}(\mathrm{a})$ and nigrosin (b). 


\subsection{PTAAM-2 $\lambda$ response to scattering and absorption}

590 Because scattering does not produce thermal effects, we do not expect photothermal instruments to be sensitive to the scattering of the sample. We generated purely scattering aerosol by nebulizing different aqueous solutions of ammonium sulfate (Figure 13). For the $532 \mathrm{~nm}$ channel, we observed a constant signal of about $1.5 \mathrm{Mm}^{-1}$ above the background. This might be caused by the presence of absorbing gases; this absorption is subtracted by the measurement of the filtered air during the offset determination, but the filtering might also remove a small part of the absorbing gases due to their adsorption on the filter fibres. For the $1064 \mathrm{~nm}$ channel, we observe a small negative signal which represents $0.2 \%$ of the reported scattering coefficient.

a)

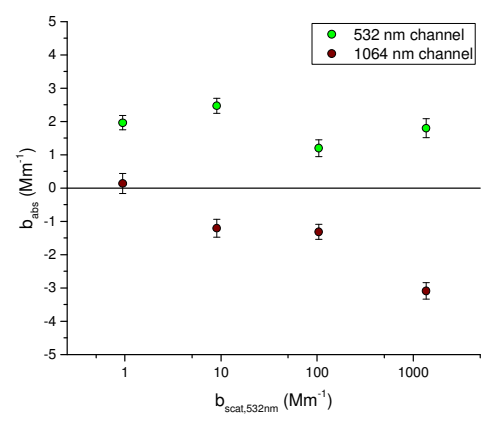

Figure 13. Scattering artefact for different samples of ammonium sulfate (a). Volume size distributions of ammonium sulfate samples (b).

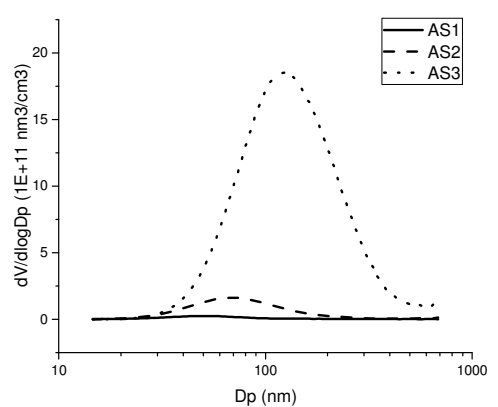

b) 


\subsection{Laboratory campaigns}

As shown, the PTAAM- $2 \lambda$ measures the aerosol absorption coefficient without size and scattering artefacts. This makes the instrument suitable to study optical properties of aerosols and the response of other absorption instruments, especially filter photometers. Thus, we have investigated filter artefacts in the Aethalometer AE33 and the CLAP. The response of the AE33 and the CLAP to purely scattering aerosol was tested using aerosolized ammonium sulfate of different sizes (Figure 14.a). The scattering artefact is most pronounced for small particles (volume size mode of $50 \mathrm{~nm}$ ) where the attenuation coefficient in green approximately equals the scattering coefficient. For larger particles it is reduced and reaches $6 \%$ at particle volume size mode of $122 \mathrm{~nm}$. These values are higher compared to the ones in Drinovec et al. (2015) where $b_{a t n} / b_{\text {scat }}$ values between $1.2 \%-3.4 \%$ were obtained for the old-type TFE-coated glass fiber filter type (Pallflex "Fiberfilm" T60A20).

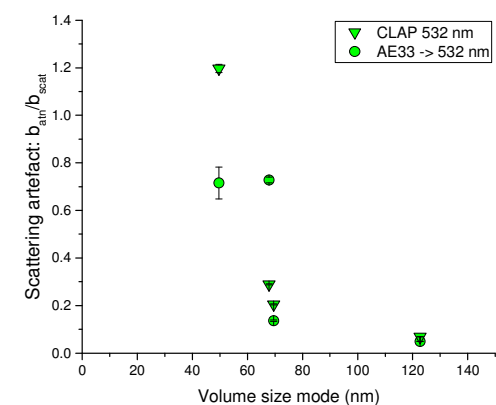

a)

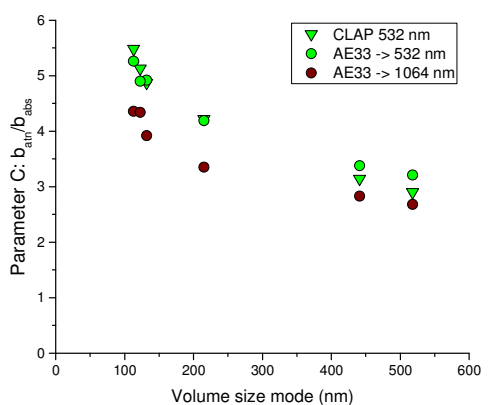

b)

Figure 14. Scattering artefact of filter photometers the CLAP and the AE33 for different sizes of ammonium sulfate particles (a). Multiple scattering parameter $\mathrm{C}$ for different sizes of soot (b). For most measurements, the standard error was smaller than the symbol.

Similarly to scattering, there is also a strong dependence of the filter photometer response on the size of absorbing particles. The enhancement of light absorption in the filter matrix relative to particles suspended in air is described by the multiple-scattering parameter C (Weingartner et al., 2003). For attenuation coefficient compensated for filter loading effect it holds that $C=b_{a t n} / b_{a b s}$. The AE33 data was extrapolated to 532 and $1064 \mathrm{~nm}$ to match the PTAAM-2 $\lambda$ wavelengths, whereas for the CLAP only the $532 \mathrm{~nm}$ signal was analysed. For both filter photometers the parameter $\mathrm{C}$ for soot samples (Section 2.3) of different sizes shows higher absorption enhancement for smaller particles compared to larger ones (Figure 14.b). The dependence of the parameter $C$ on the size is quite steep at lower and atmospherically relevant sizes, then it levels off. For the AE33, the parameter $C$ decreases at $532 \mathrm{~nm}$ from 5.3 to 3.2 , and at $1064 \mathrm{~nm}$ from 4.4 to 2.7 when the volume size mode increases from $100 \mathrm{~nm}$ to $500 \mathrm{~nm}$. These values are higher compared to the values between 2.8 and 3.6 obtained by Bernardoni et al. (2020), Yus-Díez et al. (2021) and Ferrero et al. (2021) at 520 and $660 \mathrm{~nm}$. Similarly to our results, Bernardoni and Ferrero observed higher values of the parameter $C$ at shorter wavelengths. The dependence of the parameter $\mathrm{C}$ on the wavelength results in erroneous determination of the absorption Ångström exponent in filter photometers - reporting about 0.17 0.3 higher values compared to the PTAAM-2 $\lambda$ (Table 3 ). 
Table 3: the AE33 systematically overestimates the absorption Ångström exponents (AAE) compared to the PTAAM-2 $\lambda$.

\begin{tabular}{|l|l|l|l|l|}
\hline Campaign & Sample & $\begin{array}{l}\text { Volume mode } \\
(\mathbf{n m})\end{array}$ & $\begin{array}{l}\text { AAE PTAAM-2 } \boldsymbol{\lambda} \\
\mathbf{5 3 2 - 1 0 6 4} \mathbf{~ n m}\end{array}$ & $\begin{array}{l}\text { AAE AE33 } \\
\mathbf{3 7 0 - 9 5 0} \mathbf{n m}\end{array}$ \\
\hline Ljubljana 2021 & Diesel soot & 123 & 1.07 & 1.26 \\
\hline AeroTox 2020 & miniCAST soot & 160 & 0.86 & 1.16 \\
\hline Ljubljana 2021 & Propane soot & 441 & 0.77 & 0.94 \\
\hline
\end{tabular}

The dependence of the AE33 measured attenuation coefficient on the sample single scattering albedo (SSA) was tested with an external mixture of propane soot (441 nm volume mode) and ammonium sulphate (123 nm volume mode). The experiment was performed by filling a barrel with soot at the start, followed by continuous injection of ammonium sulphate particles (Figure 15). SSA increased from 0.25 to 0.997 . There is an increase in attenuation ratio batn $\mathrm{n}_{532 \mathrm{~nm}} / \mathrm{babs}_{532 \mathrm{~nm}}$ shortly after the start of the experiment, but after the filter change (at 14:28) the ratio returns to the initial value, which indicates that the filter loading compensation was not working optimally for the selected sample. The second filter spot loading was lower and did not affect the measurement - the attenuation ratio shows a big increase for SSA>0.995 where the AE33 signal is more than doubled. This effect has been observed in ambient measurements when the AE33 was compared to a MAAP in three different sites (Yus-Díez et al., 2021). The increase of the ratio was more than three-fold at regional background sites during the periods of high SSA.

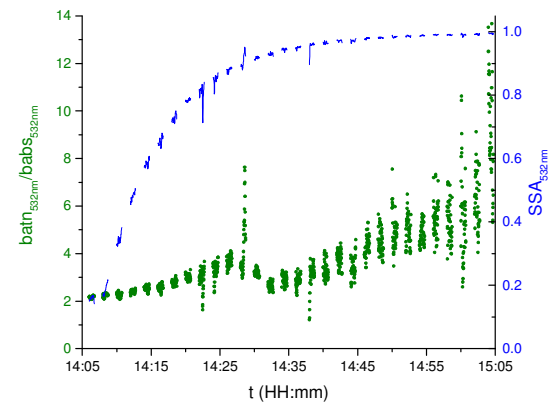

a)

Figure 15. Measurement of externally mixed diesel soot and ammonium sulphate. The ratio between the AE33 attenuation coefficient and the PTAAM- $2 \lambda$ absorption coefficient and singlescattering albedo as a function of time (a). There was a filter change for the AE33 at 14:28. Attenuation to absorption ratio as a function of the single-scattering albedo (b). 


\subsection{Winter ambient campaign}

655 The winter campaign was carried out in Ljubljana (Slovenia) in February and March 2020 to evaluate the PTAAM- $2 \lambda$ performance for ambient measurements. Absorption above $30 \mathrm{Mm}^{-1}$ at $532 \mathrm{~nm}$ was measured regularly during the night (Figure 16). During the day the absorption was lower, making it difficult to determine the Ångström exponent with a high time resolution - as the instrument was operating with a higher than normal noise level. Comparisons with the AE33 show similar parameter $C$ values (Figure 16c-d) as obtained for larger particles during the laboratory campaign. Ångström exponents in the range between 0.8 and 1.4 have been obtained, with the AE33 providing 0.3 higher AAE values. For more precise ambient measurements the instrument noise at $1 \mathrm{~s}$ time resolution should be reduced to $1 \mathrm{Mm}^{-1}$ or lower.

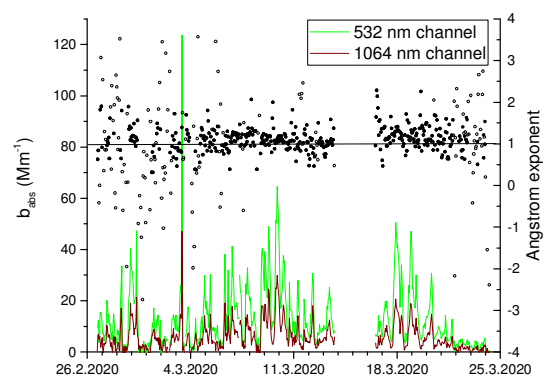

a)

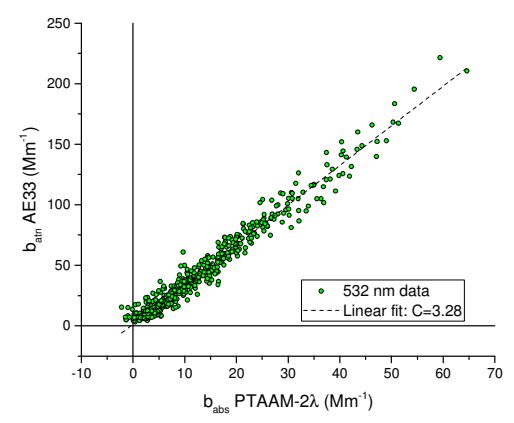

c)

Figure 16. Absorption coefficient and Ångström exponent measured during the Ljubljana 2020 winter campaign (a) and a frequency distribution of the Ångström exponent (b). Correlations between attenuation coefficient and absorption coefficient for the $532 \mathrm{~nm}$ channel (c) and the $1064 \mathrm{~nm}$ channel (d). b)
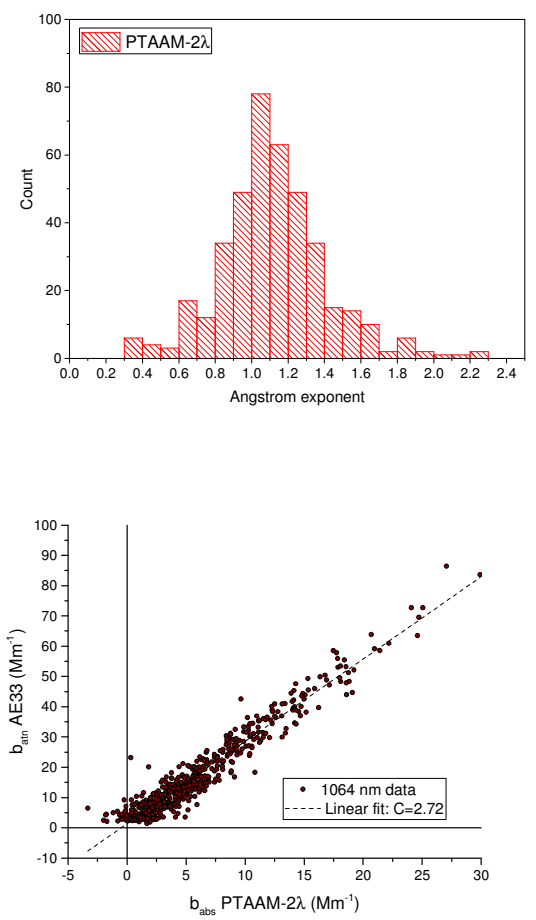

d)

670 


\subsection{Uncertainty analysis}

675 The uncertainty of the measured absorption coefficient results from the calibration, method and instrumental uncertainties. The calibration of the $532 \mathrm{~nm}$ channel depends strongly on the uncertainty of $\mathrm{NO}_{2}$ amount fraction in the calibrating gas mixture. The standard uncertainty of $\mathrm{NO}_{2}$ amount fraction produced by TMPG was below $2 \%$. The calibration of the $1064 \mathrm{~nm}$ channel depends both on the uncertainty of the $532 \mathrm{~nm}$ channel and the uncertainty of the nigrosin absorption ratio $\mathrm{b}_{\mathrm{abs}, 1064 \mathrm{~nm}} / \mathrm{b}_{\mathrm{abs}, 532 \mathrm{~nm}}$; this parameter depends on the correct determination of the nigrosin refractive index and the measured size distribution. Determination of the refractive index is sensitive to the variation of nigrosin sample thickness which influence the reflectivity of thin film; resulting uncertainy of $3 \%$ is assessed. For well serviced SMPS instruments, the uncertainty is below $10 \%$ (Wiedensohler et al, 2017), the uncertainty of the ratio of the absorption coefficients is lower, resulting in $4 \%$ uncertainty. Instrument operation can be influenced by the scattering artefact and the presence of absorbing gases. The absorption of gases is subtracted by measurement of filtered air, but small amouth of the gas can be adsorbed to the filter material. The combined uncertainty of scattering and gases of $1 \%$ is assessed. The final uncertainty contribution comes from the stability of the instrument response (3\%).

690 Combined standard uncertainties for the determination of absorption coefficients and absorption Ångström exponent are presented in Table 4. The $1064 \mathrm{~nm}$ channel uncertainty (6\%) is higher compared to the $532 \mathrm{~nm}$ channel $(4 \%)$ due to the additional calibrations step with nigrosin particles. The uncertainty of the absorption Ångström exponent (9\%) is higher compared to the absorption coefficients because of the properties of the logarithmic function.

Table 4. The sources of uncertainty for PTAAM-2 $\lambda$ measurements and combined standard uncertainties ( $k=1$ ) for obtaining absorption coefficients and absorption Ångström exponent (AAE). Combined uncertainties were calculated using independent uncertainty components.

\begin{tabular}{|l|l|l|l|}
\hline & Sources of uncertainty & Uncertainty & Components \\
\hline $\mathrm{A}$ & $\mathrm{NO}_{2}$ amount fraction & $2 \%$ & \\
\hline $\mathrm{B}$ & Nigrosin refractive index & $3 \%$ & \\
\hline $\mathrm{C}$ & Mie calculation of $\mathrm{b}_{\mathrm{abs}, 1064 \mathrm{~nm}} / \mathrm{b}_{\mathrm{abs}, 532 \mathrm{~nm}}$ & $4 \%$ & \\
\hline $\mathrm{D}$ & Scattering \& absorbing gases & $1 \%$ & \\
\hline $\mathrm{E}$ & Stability of instrument & $3 \%$ & \\
\hline & Combined uncertainties & & \\
\hline & $\mathrm{b}_{\mathrm{abs}, 532 \mathrm{~nm}}$ & $4 \%$ & $\mathrm{~A}, \mathrm{D}, \mathrm{E}$ \\
\hline & $\mathrm{b}_{\mathrm{abs}, 1064 \mathrm{~nm}}$ & $6 \%$ & $\mathrm{~A}, \mathrm{~B}, \mathrm{C}, \mathrm{D}, \mathrm{E}$ \\
\hline & $\mathrm{AAE}$ & $9 \%$ & $\mathrm{~B}, \mathrm{C}, \mathrm{D}, \mathrm{E}, \mathrm{In}$ \\
\hline
\end{tabular}




\section{Conclusions}

We report on the design and operation of the first dual-wavelength photothermal interferometer (PTAAM-2 $\lambda$ ) for measurements of aerosol absorption. The instrumental design allows for simultaneous measurement of the same sample at both wavelengths.

The instrument was calibrated with $\mathrm{NO}_{2}$ at $532 \mathrm{~nm}$ and the calibration was transferred to $1064 \mathrm{~nm}$ using aerosolized nigrosin. We were able to use Mie theory to calculate the ratio of the absorption coefficients at the two wavelengths due to the spherical shape of these particles. The comparison of this modelled absorption coefficient with the measured one for polydisperse nigrosin at $532 \mathrm{~nm}$ shows a $6 \%$ and $24 \%$ difference for the AeroTox 2020 and Ljubljana 2021 campaigns, correspondingly. This validates our approach.

The PTAAM- $2 \lambda$ is one of the few instruments able to measure aerosol absorption coefficients at high SSA. We have demonstrated the long-term stability of the instrument and shown that the determination of the absorption coefficient is artefact-free. Uncertainties of $4 \%, 6 \%$ and $9 \%$ were determined for the absorption coefficients at $532 \mathrm{~nm}, 1064 \mathrm{~nm}$ and absorption Ångström exponent, respectively. We have used the dual-wavelength photothermal interferometer to determine the artefacts of filter photometers and quantify their dependence on the wavelength and the aerosol size. The PTAAM- $2 \lambda$ shows lower AAE compared to filter photometers, demonstrating a wavelength dependence of the filter photometer multiple-scattering parameter $\mathrm{C}$. We have also shown how the quantification of the filter photometer sensitivity on the aerosol size is determined and that for low SSA, filter photometers perform satisfactorily if correct values of parameter $\mathrm{C}$ are used.

We believe that the demonstrated operation and performance makes the PTAAM- $2 \lambda$ a strong candidate for reference measurements of the aerosol absorption coefficient. 
Data availability. The raw data and measurement logs are available at http://repozitorij.ung.si/Dokument.php?id=23720. Additional related data can be made available upon request.

Competing interests. LD, GM and UJ are or were employed by Haze Instruments d.o.o., the manufacturer of the described instrument. Technologies described here-in have been protected with patents.

Author contributions. LD and GM designed and developed the PTAAM- $2 \lambda$. LD carried out the majority of experiments and analyzed the data. EW, BV and JR provided input into the experimental design of the photothermal interferometer. UJ performed measurements of nigrosin refractive index and laser spectra. LP performed scanning electron microscopy. MŠ performed measurements with atomic force microscope. MK performed integrating sphere measurements, KVi performed SMPS measurements during Ljubljana 2021 campaign. LF and UJ performed Mie calculations and quality control. DMK and KVa carried out experiments during AeroTox 2020 campaign. TB and CP prepared and tested Tracabel Mobile Permeation Generator of $\mathrm{NO}_{2}$ for PTAAM- $2 \lambda$ calibration. TM and AW collaborated with nephelometer measurements and calibration. LD and GM wrote the paper with other authors providing valuable additions. All co-authors contributed to the paper discussion and revision.

740 Acknowledgement. We thank Martin Gysel (PSI) for the use of the AE33, Teledyne API and EAS Envimet Analytical Systems $\mathrm{GmbH}$ for the loan of the $\mathrm{NO}_{2}$ CAPS. We thank AMES d.o.o. for the technical support.

Financial support. This research has been supported by the Swiss National Science Foundation (grant no. 200021_172649), EUROSTARS programme (IMALA, grant no. 11386), Slovenian Research Agency

745 grants P1-0385, P1-0099 and I-0033, and the European Metrology Programme for Innovation and Research (EMPIR Black Carbon, EMPIR AeroTox). 


\section{References}

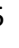

Arnott, W. P., Moosmüller, H., and Walker, J. W.: Nitrogen dioxide and kerosene-flame soot calibration of photoacoustic instruments for measurements of light absorption by aerosols, Rev. Sci. Instr., 71, 4545-4552, https://doi.org/10.1063/1.1322585, 2000.

Arnott, W. P., Moosmuller, H., Sheridan, P. J., Ogren, J. A., Raspet, R., Slaton, W. V., Hand, J. L., Kreidenweis, S. M., and Collett, J. L.: Photoacoustic and filter-based ambient aerosol light absorption measurements: Instrument comparisons and the role of relative humidity, Journal of Geophysical Research-Atmospheres, 108, 10.1029/2002jd002165, 2003.

Arnott, W. P., Hamasha, K., Moosmüller, H., Sheridan, P. J., and Ogren, J. A.: Towards Aerosol LightAbsorption Measurements with a 7-Wavelength Aethalometer: Evaluation with a Photoacoustic Instrument and 3-Wavelength Nephelometer, Aerosol Sci. Tech., 39, 17-29, 10.1080/027868290901972, 2005.

Bernardoni, V., Ferrero, L., Bolzacchini, E., Forello, A. C., Gregorič, A., Massabò, D., Močnik, G., Prati, P., Rigler, M., Santagostini, L., Soldan, F., Valentini, S., Valli, G., and Vecchi, R.: Determination of Aethalometer multiple-scattering enhancement parameters and impact on source apportionment during the winter 2017/18 EMEP/ACTRIS/COLOSSAL campaign in Milan, Atmos. Meas. Tech., 14, 2919-2940, https://doi.org/10.5194/amt-14-2919-2021, 2021.

Bluvshtein, N., Flores, J. M., He, Q., Segre, E., Segev, L., Hong, N., Donohue, A., Hilfiker, J. N., and Rudich, Y.: Calibration of a multi-pass photoacoustic spectrometer cell using light-absorbing aerosols, Atmos. Meas. Tech., 10, 1203-1213, https://doi.org/10.5194/amt-10-1203-2017, 2017.

Bond, T. C., Anderson, T. L., and Campbell, D.: Calibration and intercomparison of filter-based measurements of visible light absorption by aerosols, Aerosol Sci. Tech., 30, 582-600, doi:10.1080/027868299304435, 1999.

Bond, T. C., Doherty, S. J., Fahey, D. W., Forster, P. M., Berntsen, T., DeAngelo, B. J., Flanner, M. G., Ghan, S., Karcher, B., Koch, D., Kinne, S., Kondo, Y., Quinn, P. K., Sarofim, M. C., Schultz, M. G., Schulz, M., Venkataraman, C., Zhang, H., Zhang, S., Bellouin, N., Guttikunda, S. K., Hopke, P. K., Jacobson, M. Z., Kaiser, J. W., Klimont, Z., Lohmann, U., Schwarz, J. P., Shindell, D., Storelvmo, T., Warren, S. G., and Zender, C. S.: Bounding the role of black carbon in the climate system: A scientific assessment, Journal of Geophysical Research-Atmospheres, 118, 5380-5552, 10.1002/jgrd.50171, 2013.

Collaud Coen, M., Weingartner, E., Apituley, A., Ceburnis, D., Fierz-Schmidhauser, R., Flentje, H., Henzing, J. S., Jennings, S. G., Moerman, M., Petzold, A., Schmid, O., and Baltensperger, U.: Minimizing light absorption measurement artifacts of the Aethalometer: evaluation of five correction algorithms, Atmos. Meas. Tech., 3, 457-474, https://doi.org/10.5194/amt-3-457-2010, 2010.

Cuesta-Mosquera, A., Močnik, G., Drinovec, L., Müller, T., Pfeifer, S., Minguillón, M. C., Briel, B., Buckley, P., Dudoitis, V., Fernández-García, J., Fernández-Amado, M., Ferreira De Brito, J., Riffault, V., Flentje, H., Heffernan, E., Kalivitis, N., Kalogridis, A.-C., Keernik, H., Marmureanu, L., Luoma, K., Marinoni, A., Pikridas, M., Schauer, G., Serfozo, N., Servomaa, H., Titos, G., Yus-Díez, J., Zioła, N., and Wiedensohler, A.: Intercomparison and characterization of 23 Aethalometers under laboratory and 
ambient air conditions: procedures and unit-to-unit variabilities, Atmos. Meas. Tech., 14, 3195-3216, https://doi.org/10.5194/amt-14-3195-2021, 2021.

Davies, N. W., Cotterell, M. I., Fox, C., Szpek, K., Haywood, J. M., and Langridge, J. M.: On the accuracy of aerosol photoacoustic spectrometer calibrations using absorption by ozone, Atmos. Meas. Tech., 11, 2313-2324, https://doi.org/10.5194/amt-11-2313-2018, 2018.

Drinovec, L., Močnik, G., Zotter, P., Prévôt, A. S. H., Ruckstuhl, C., Coz, E., Rupakheti, M., Sciare, J., Müller, T., Wiedensohler, A., and Hansen, A. D. A.: The "dual-spot" Aethalometer: an improved measurement of aerosol black carbon with real-time loading compensation, Atmos. Meas. Tech., 8 , 1965-1979, 10.5194/amt-8-1965-2015, 2015.

Drinovec, L., Gregorič, A., Zotter, P., Wolf, R., Bruns, E. A., Prévôt, A. S. H., Petit, J.-E., Favez, O., Sciare, J., Arnold, I. J., Chakrabarty, R. K., Moosmüller, H., Filep, A., and Močnik, G.: The filter-loading effect by ambient aerosols in filter absorption photometers depends on the coating of the sampled particles, Atmos. Meas. Tech., 10, 1043-1059, 10.5194/amt-10-1043-2017, 2017.

Drinovec L. and Močnik G.: Photo-thermal interferometer, Euopean Patent office, European Patent Specification EP3 492905 B1, 2020-04-29, 2020.

Ess, M. N., Bertò, M., Irwin, M., Modini, R. L., Gysel-Beer, M., and Vasilatou, K.: Optical and morphological properties of soot particles generated by the miniCAST 5201 BC generator, Aerosol Sci. Technol., 0, 1-25, https://doi.org/10.1080/02786826.2021.1901847, 2021.

Ferrero, L., Castelli, M., Ferrini, B. S., Moscatelli, M., Perrone, M. G., Sangiorgi, G., D'Angelo, L., Rovelli, G., Moroni, B., Scardazza, F., Močnik, G., Bolzacchini, E., Petitta, M., and Cappelletti, D.: Impact of black carbon aerosol over Italian basin valleys: high-resolution measurements along vertical profiles, radiative forcing and heating rate, Atmos. Chem. Phys., 14, 9641-9664, https://doi.org/10.5194/acp-14-9641-2014, 2014.

Ferrero, L., Gregorič, A., Močnik, G., Rigler, M., Cogliati, S., Barnaba, F., Di Liberto, L., Gobbi, G. P., Losi, N., and Bolzacchini, E.: The impact of cloudiness and cloud type on the atmospheric heating rate of black and brown carbon in the Po Valley, Atmos. Chem. Phys., 21, 4869-4897, https://doi.org/10.5194/acp-21-4869-2021, 2021.

Flores, E., Viallon, J., Idrees, F., Moussay, P., Wielgosz, R., Shinji, UI., Cieciora, D., Rolle, F., Sega, M., Sang-Hyub, O., Macé, T., Sutour, C., Pascale, C., Zhang, T., Wang, D., Guo, H., Han, Q., Smeulders, D., Jozela, M., Ntsasa, N.G.m, Tshilongo, J., Mphamo, T., Van Aswegen, S., Worton, D., Brewer, P., Valkova, M., Tarhan, T., Efremova, O., Konopelko, L., de Krom, I., Persijn, S. and van der Veen, A.: Final report on international comparison CCQM-K74: Nitrogen dioxide, $10 \mu \mathrm{mol} / \mathrm{mol}$, Metrologia, 58(1A), https://doi.org/10.1088/0026-1394/58/1A/08018, 2021.

Foster, K., Pokhrel, R., Burkhart, M., and Murphy, S.: A novel approach to calibrating a photoacoustic absorption spectrometer using polydisperse absorbing aerosol, Atmos. Meas. Tech., 12, 3351-3363, https://doi.org/10.5194/amt-12-3351-2019, 2019.

Haerri, H.-P., Macé, T., Waldén, J., Pascale, C., Niederhauser, B., Wirtz, K., Stovcik, V., Sutour, C., Couette, J., and Waldén, T.: Dilution and permeation standards for the generation of NO, NO2 and 
SO2 calibration gas mixtures, Meas. Sci. Technol., 28, 035801, https://doi.org/10.1088/13616501/aa543d, 2017.

Hyvärinen, A.-P., Vakkari, V., Laakso, L., Hooda, R. K., Sharma, V. P., Panwar, T. S., Beukes, J. P., van Zyl, P. G., Josipovic, M., Garland, R. M., Andreae, M. O., Pöschl, U., and Petzold, A.: Correction for a measurement artefact of the Multi-Angle Absorption Photometer (MAAP) at high black carbon mass concentration levels, Atmos. Meas. Tech., 6, 81-90, doi:10.5194/amt-6-81-2013, 2013.

Janssen, N. A., Gerlofs-Nijland, M. E., Lanki, T., Salonen, R. O., Cassee, F., Hoek, G., Fischer, P., Brunekreef, B., and Krzyzanowski, M.: Health Effects of Black Carbon, World Health Organization, 2012.

Janssen, N. A. H., Hoek, G., Simic-Lawson, M., Fischer, P., van Bree, L., ten Brink, H., Keuken, M., Atkinson, R. W., Anderson, H. R., Brunekreef, B., and Cassee, F. R.: Black Carbon as an Additional Indicator of the Adverse Health Effects of Airborne Particles Compared with PM10 and PM2.5, Environ. Health Persp., 119, 1691-1699, 10.1289/ehp.1003369, 2011.

JCGM - Joint Committee for Guides in Metrology: Evaluation of Measurement Data-Guide to the Expression of Uncertainty in Measurement (GUM) vol 100, 1st edn (Paris, France: Bureau International de Poids et Mesures), www.bipm.org/en/publications/guides/gum.html (Accessed 3 January 2017), 2008.

Ježek, I., Drinovec, L., Ferrero, L., Carriero, M., and Močnik, G.: Determination of car on-road black carbon and particle number emission factors and comparison between mobile and stationary measurements, Atmos. Meas. Tech., 8, 43-55, https://doi.org/10.5194/amt-8-43-2015, 2015.

Kalbermatter, D. M., Močnik, G., Drinovec, L., Visser, B., Röhrbein, J., Oscity, M., Weingartner, E., Hyvärinen, A.-P., and Vasilatou, K.: Response of black carbon and aerosol absorption measuring instruments to laboratory-generated soot coated with controlled amounts of secondary organic matter, Atmos. Meas. Tech., doi.org/10.5194/amt-2021-214, 2021.

Kirchstetter, T.W., Novakov, T., and Hobbs, P. V.: Evidence that the spectral dependence of light absorption by aerosols is affected by organic carbon, J. Geophys. Res.-Atmos., 109, D21208, doi:10.1029/2004JD004999, 2004.

Kumar, N. K., Corbin, J. C., Bruns, E. A., Massabó, D., Slowik, J. G., Drinovec, L., Močnik, G., Prati, P., Vlachou, A., Baltensperger, U., Gysel, M., El-Haddad, I., and Prévôt, A. S. H.: Production of particulate brown carbon during atmospheric aging of residential wood-burning emissions, Atmos. Chem. Phys., 18, 17843-17861, https://doi.org/10.5194/acp-18-17843-2018, 2018.

855 Lack, D. A., Lovejoy, E. R., Baynard, T., Pettersson, A., and Ravishankara, A. R.: Aerosol absorption measurement using photoacoustic spectroscopy: Sensitivity, calibration, and uncertainty developments, Aerosol Sci. Tech., 40, 697-708, https://doi.org/10.1080/02786820600803917, 2006.

Lack, D. A., Cappa, C. D., Covert, D. S., Baynard, T., Massoli, P., Sierau, B., Bates, T. S., Quinn, P. K., Lovejoy, E. R., and Ravishankara, A. R.: Bias in filter-based aerosol light absorption measurements 1041, https://doi.org/10.1080/02786820802389277, 2008. 
Lack, D. A., Cappa, C. D., Cross, E. S., Massoli, P., Ahern, A. T., Davidovits, P., and Onasch, T. B.: Absorption Enhancement of Coated Absorbing Aerosols: Validation of the Photo-Acoustic Technique for Measuring the Enhancement, Aerosol Sci. Tech., 43, 1006-1012, https://doi.org/10.1080/02786820903117932, 2009.

Lack, D. A., Richardson, M. S., Law, D., Langridge, J. M., Cappa, C. D., McLaughlin, R. J., and Murphy, D. M.: Aircraft instrument for comprehensive characterization of aerosol optical properties, part 2: Black and brown carbon absorption and absorption enhancement measured with photo acoustic spectroscopy, Aerosol Sci. Tech., 46, 555-568, https://doi.org/10.1080/02786826.2011.645955, 2012.

Langridge, J. M., Richardson, M. S., Lack, D. A., Brock, C. A., and Murphy, D. M.: Limitations of the Photoacoustic Technique for Aerosol Absorption Measurement at High Relative Humidity, Aerosol Sci. Tech., 47, 1163-1173, 10.1080/02786826.2013.827324, 2013.

Lee, J., and Moosmüller, H.: Measurement of Light Absorbing Aerosols with Folded-Jamin Photothermal Interferometry, Sensors (Basel), 20, 10.3390/s20092615, 2020.

Mätzler C.: MATLAB Functions for Mie Scattering and Absorption, IAP Research Report No. 2002-08, Institute of Applied Physics, University of Bern, 2002

Modini, R. L., Corbin, J. C., Brem, B. T., Irwin, M., Bertò, M., Pileci, R. E., Fetfatzis, P., Eleftheriadis, K., Henzing, B., Moerman, M. M., Liu, F., Müller, T., and Gysel-Beer, M.: Detailed characterization of the CAPS single-scattering albedo monitor (CAPS PMssa) as a field-deployable instrument for measuring aerosol light absorption with the extinction-minus-scattering method, Atmos. Meas. Tech., 14, 819851, https://doi.org/10.5194/amt-14-819-2021, 2021.

Moosmüller, H., and Arnott, W. P.: Folded Jamin interferometer: A stable instrument for refractiveindex measurements, Opt. Lett., 21, 438-440, 10.1364/ol.21.000438, 1996.

Moosmüller, H., Chakrabarty, R. K., and Arnott, W. P.: Aerosol light absorption and its measurement: A review, Journal of Quantitative Spectroscopy \& Radiative Transfer, 110, 844-878, 10.1016/j.jqsrt.2009.02.035, 2009.

Müller, T., Henzing, J. S., de Leeuw, G., Wiedensohler, A., Alastuey, A., Angelov, H., Bizjak, M., Collaud Coen, M., Engström, J. E., Gruening, C., Hillamo, R., Hoffer, A., Imre, K., Ivanow, P., Jennings, G., Sun, 890 J. Y., Kalivitis, N., Karlsson, H., Komppula, M., Laj, P., Li, S.-M., Lunder, C., Marinoni, A., Martins dos Santos, S., Moerman, M., Nowak, A., Ogren, J. A., Petzold, A., Pichon, J. M., Rodriquez, S., Sharma, S., Sheridan, P. J., Teinilä, K., Tuch, T., Viana, M., Virkkula, A., Weingartner, E., Wilhelm, R., and Wang, Y. Q.: Characterization and intercomparison of aerosol absorption photometers: result of two intercomparison workshops, Atmos. Meas. Tech., 4, 245-268, https://doi.org/10.5194/amt-4-2452011, 2011.

Murphy, D. M.: The Effect of Water Evaporation on Photoacoustic Signals in Transition and Molecular Flow, Aerosol Sci. Tech., 43, 356-363, 10.1080/02786820802657392, 2009. 
Nakayama, T., Suzuki, H., Kagamitani, S., Ikeda, Y., Uchiyama, A., and Matsumi, Y.: Characterization of a Three Wavelength Photoacoustic Soot Spectrometer (PASS-3) and a Photoacoustic Extinctiometer (PAX), J. Meteorol. Soc. Ser. II, 93, 285-308, 10.2151/jmsj.2015-016, 2015.

Ogren, J. A., Wendell, J., Andrews, E., and Sheridan, P. J.: Continuous light absorption photometer for long-term studies, Atmos. Meas. Tech., 10, 4805-4818, 10.5194/amt-10-4805-2017, 2017.

Petzold, A., Kramer, H., and Schönlinner, M.: Continuous measurement of atmospheric black carbon using a multi-angle absorption photometer, Environ. Sci. Pollut. Res, 4, 78-82, 2002.

Petzold, A., Ogren, J. A., Fiebig, M., Laj, P., Li, S. M., Baltensperger, U., Holzer-Popp, T., Kinne, S., Pappalardo, G., Sugimoto, N., Wehrli, C., Wiedensohler, A., and Zhang, X. Y.: Recommendations for reporting "black carbon" measurements, Atmos. Chem. Phys, 13, 8365-8379, 10.5194/acp-13-83652013, 2013.

Petzold, A., Onasch, T., Kebabian, P., and Freedman, A.: Intercomparison of a Cavity Attenuated Phase Shift-based extinction monitor (CAPS PMex) with an integrating nephelometer and a filterbased absorption monitor, Atmos. Meas. Tech., 6, 1141-1151, https://doi.org/10.5194/amt-6-11412013, 2013.

Rosen, H., Hansen, A. D. A., Gundel, L., and Novakov, T.: Identification of the optically absorbing component in urban aerosols, Appl. Opt., 17, 3859-3861, https://doi.org/10.1364/A0.17.003859, 1978.

Saleh, R., Hennigan, C. J., McMeeking, G. R., Chuang, W. K., Robinson, E. S., Coe, H., Donahue, N. M., and Robinson, A. L.: Absorptivity of brown carbon in fresh and photo-chemically aged biomassburning emissions, Atmos. Chem. Phys., 13, 7683-7693, https://doi.org/10.5194/acp-13-7683-2013, 2013.

Sandradewi, J., Prévôt, A.S.H., Szidat, S., Perron, N., Alfarra, M.R., Lanz, V.A., Weingartner, E., Baltensperger, U.: Using aerosol light absorption measurements for the quantitative determination of wood burning and traffic emission contributions to particulate matter. Environ. Sci. Tech., 42, 3316-23. https://doi.org/10.1021/es702253m, 2008.

Schnaiter, M., Gimmler, M., Llamas, I., Linke, C., Jäger, C., and Mutschke, H.: Strong spectral dependence of light absorption by organic carbon particles formed by propane combustion, Atmos. Chem. Phys., 6, 2981-2990, https://doi.org/10.5194/acp-6-2981-2006, 2006.

Sedlacek, A. J.: Real-time detection of ambient aerosols using photothermal interferometry: Folded Jamin interferometer, Rev. Sci. Instr., 77, 10.1063/1.2205623, 2006.

Sedlacek, A., and Lee, J.: Photothermal interferometric aerosol absorption spectrometry, Aerosol Science and Technology, 41, 1089-1101, 10.1080/02786820701697812, 2007.

USEPA - U.S. Environmental Protection Agency, Specialty Gas Producer Requirements for the Sale of EPA Protocol Gas NO2 Standards, Office of Air Quality Planning and Standards, Air Quality Assessment Division, Ambient Air Monitoring Group, October 25, 2017, https://www.epa.gov/sites/default/files/2017- 
11/documents/no2_cylinder_guidance_for_gas_producers_v3.0.pdf (last access: 21 September 2021), 2017.

Vandaele, A. C., Hermans, C., Fally, S., Carleer, M., Colin, R., Merienne, M. F., Jenouvrier, A., and Coquart, B.: High-resolution Fourier transform measurement of the NO2 visible and nearinfrared absorption cross sections: Temperature and pressure effects, J Geophys Res-Atmos, 107, 13, 10.1029/2001jd000971, 2002.

Virkkula, A.: Modeled source apportionment of black carbon particles coated with a light-scattering shell, Atmos. Meas. Tech. Discuss., https://doi.org/10.5194/amt-2020-438, accepted, 2020.

Virkkula, A., Mäkelä, T., Hillamo, R., Yli-Tuomi, T., Hirsikko, A., Hämeri, K., and Koponen, I. K.: A simple procedure for correcting loading effects of aethalometer data, J. Air Waste Manage., 57, 1214-1222, doi:10.3155/1047-3289.57.10.1214, 2007.

Visser, B., Röhrbein, J., Steigmeier, P., Drinovec, L., Močnik, G., and Weingartner, E.: A single-beam photothermal interferometer for in situ measurements of aerosol light absorption, Atmos. Meas. Tech., 13, 7097-7111, https://doi.org/10.5194/amt-13-7097-2020, 2020.

Weingartner, E., Saathoff, H., Schnaiter, M., Streit, N., Bitnar, B., and Baltensperger, U.: Absorption of light by soot particles: determination of the absorption coefficient by means of aethalometers, $\mathrm{J}$. Aerosol Sci., 34, 1445-1463, 2003.

Wiedensohler, A., Wiesner, A., Weinhold, K., Birmili, W., Hermann, M., Merkel, M., Müller, T., Pfeifer, S., Schmidt, A., Tuch, T., Velarde, F., Quincey, P., Seeger, S., and Nowak, A.: Mobility particle size spectrometers: Calibration procedures and measurement uncertainties, Aerosol Sci. Technol., 52, 146-164, https://doi.org/10.1080/02786826.2017.1387229, 2018.

Yus-Díez, J., Bernardoni, V., Močnik, G., Alastuey, A., Ciniglia, D., Ivančič, M., Querol, X., Perez, N., Reche, C., Rigler, M., Vecchi, R., Valentini, S., and Pandolfi, M.: Determination of the multiplescattering correction factor and its cross-sensitivity to scattering and wavelength dependence for different AE33 Aethalometer filter tapes: a multi-instrumental approach, Atmos. Meas. Tech., 14, 6335-6355, https://doi.org/10.5194/amt-14-6335-2021, 2021

Zanatta, M., Gysel, M., Bukowiecki, N., Muller, T., Weingartner, E., Areskoug, H., Fiebig, M., Yttri, K. E., Mihalopoulos, N., Kouvarakis, G., Beddows, D., Harrison, R. M., Cavalli, F., Putaud, J. P., Spindler, G., Wiedensohler, A., Alastuey, A., Pandolfi, M., Sellegri, K., Swietlicki, E., Jaffrezo, J. L., Baltensperger, U., and Laj, P.: A European aerosol phenomenology-5: Climatology of black carbon optical properties

965 at 9 regional background sites across Europe, Atmospheric Environment, 145, 346-364, 10.1016/j.atmosenv.2016.09.035, 2016.

Zhang, Y., Favez, O., Canonaco, F., Liu, D., Močnik, G., Amodeo, T., Sciare, J., Prévôt, A. S. H., Gros, V., and Albinet, A.: Evidence of major secondary organic aerosol contribution to lensing effect black carbon absorption enhancement, npj Climate and Atmospheric Science, 1, 10.1038/s41612-0180056-2, 2018.

Zotter, P., Herich, H., Gysel, M., El-Haddad, I., Zhang, Y., Močnik, G., Hüglin, C., Baltensperger, U., Szidat, S., and Prévôt, A. S. H.: Evaluation of the absorption Ångström exponents for traffic and wood 
https://doi.org/10.5194/amt-2022-21

Atmospheric

Preprint. Discussion started: 22 February 2022

(C) Author(s) 2022. CC BY 4.0 License.

burning in the Aethalometer-based source apportionment using radiocarbon measurements of ambient aerosol. Atmos. Chem. Phys, 17, 4229-4249, https://doi.org/10.5194/acp-17-4229-2017,

2017. 